\title{
Metal-Support Synergy of Supported Gold Nanoclusters in Selective Oxidation of Alcohols
}

\author{
Lu Liu ${ }^{1, \dagger}{ }^{\dagger}$ Huayin $\mathrm{Li}^{1,+}{ }^{\dagger}$, Yuan Tan ${ }^{1, *}$, Xingkun Chen ${ }^{1}$, Ronghe Lin ${ }^{1}$, Wenshao Yang ${ }^{1}$, \\ Chuanqi Huang ${ }^{1}$, Saisai Wang ${ }^{1}$, Xuepeng Wang ${ }^{1}$, Xiao Yan Liu ${ }^{2}$, Min Zhao ${ }^{3,4}$ and \\ Yunjie Ding ${ }^{1,3,4, *}$ \\ 1 Hangzhou Institute of Advanced studies, Zhejiang Normal University, Hangzhou 311231, China; \\ luliu1022@foxmail.com (L.L.); lihuayin@zjnu.edu.cn (H.L.); cxklned@zjnu.cn (X.C.); \\ catalysis.lin@zjnu.edu.cn (R.L.); wenshaoyang@zjnu.cn (W.Y.); hchuanqi@foxmail.com (C.H.); \\ sswang11235@163.com (S.W.); uepengwang94@zjnu.edu.cn (X.W.) \\ 2 CAS Key Laboratory of Science and Technology on Applied Catalysis, Dalian Institute of Chemical Physics, \\ Chinese Academy of Sciences, Dalian 116023, China; xyliu2003@dicp.ac.cn \\ 3 Dalian National Laboratory for Clean Energy, Dalian Institute of Chemical Physics, Chinese Academy of \\ Sciences, Dalian 116023, China; zhaomin162@dicp.ac.cn \\ 4 The State Key Laboratory of Catalysis, Dalian Institute of Chemical Physics, Chinese Academy of Sciences, \\ Dalian 116023, China \\ * Correspondence: yuantan2012@zjnu.edu.cn (Y.T.); dyj@dicp.ac.cn (Y.D.); \\ Tel.: +86-571-8225-7902 (Y.T.); +86-411-8437-9143 (Y.D.) \\ + These authors contributed equally to this work and should be considered as the co-first authors.
}

Received: 25 December 2019; Accepted: 8 January 2020; Published: 11 January 2020

check for updates

\begin{abstract}
Gold catalysts have been reported to exhibit good performance in aerobic oxidation of alcohols, but the intrinsic origin of the catalytic reactivity is still illusive. The catalyst preparation method, the morphology of the gold particles, and even the support might be key factors that determine the activity. Here, we prepared a series of gold catalysts with different supports, i.e., the hydrotalcite (HT), $\mathrm{ZnO}, \mathrm{MgO}, \mathrm{Al}_{2} \mathrm{O}_{3}$, and $\mathrm{SiO}_{2}$, by using the atomically controlled $\mathrm{Au}_{25}$ nanoclusters (NCs) as the gold precursor. The characterization results of the X-ray diffraction (XRD), UV-vis and transmission electron microscopy (TEM) show that the gold particles were mostly uniformly distributed on the supports, with a mean particle size within $3 \mathrm{~nm}$. In aerobic oxidation of benzyl alcohol, the MgAl-HTand $\mathrm{Al}_{2} \mathrm{O}_{3}$-supported $\mathrm{Au}_{25} \mathrm{NCs}$ display good performances, with turnover frequency (TOF) values of $\sim 2927$ and $2892 \mathrm{~h}^{-1}$, respectively, whereas the $\mathrm{SiO}_{2-}, \mathrm{MgO}-$, and $\mathrm{ZnO}$-supported analogues show much inferior activity. The high resolution TEM and X-ray photoelectron spectra (XPS) results suggest that the interactions between gold and the supports in different samples are differing, which influences the morphology and the nature of gold. Our results further point to the importance of acid-base property of the support and the metal-support synergy rather than the gold particle size alone in achieving high-performance in selective alcohol oxidation. Moreover, this work provided a good way to design gold catalysts with controllable sizes that is crucial for understanding the reaction process in aerobic oxidation of alcohol.
\end{abstract}

Keywords: gold nanocluster; supported catalysts; aerobic oxidation of alcohols; support effect; size effect

\section{Introduction}

Supported gold catalysts have attracted a lot of attention in the past few decades because of Hutchings and Haruta's pioneer work [1,2]. Highly dispersed gold nanocatalysts displayed good performances in various reactions, including the low temperature $\mathrm{CO}$ oxidation [2-6], chemoselective 
hydrogenation of fine chemicals [7-10], C-C cross-coupling reactions [11-13], selective oxidation of alcohols [14-20], etc. This remarkable catalytic behavior of gold catalysts renders them potential candidates for both fundamental research and the industrial community.

Selective oxidation of alcohols to the corresponding aldehyde and ketone is one of most important processes in fundamental and industrial research. Since the aldehyde and ketone were used as the key intermediates in fine chemical synthesis such as perfume, pesticide, and pharmaceuticals $[10,16]$. Among them, the benzaldehyde is one of the representatives in aromatic-aldehydes due to the simple structure and wide applications. In traditional industrial production, the manufacturing of benzaldehyde could be reached by the vapor/liquid phase air oxidation of toluene and the hydrolysis of dichloromethylbenzene [16,21]. However, these processes involve the stoichiometric oxidants or hazardous substances, which was not environmentally friendly [22]. Using $\mathrm{O}_{2}$ as the oxygen source instead of the stoichiometric oxidants has attracted great interest recently with respect to the economic and environmental reasons [17-20]. Nevertheless, these processes remain challenging regarding the selectivity issues since the benzyl alcohol could be overoxidized to form acid and other by-products [21,22]. Thus, developing green and sustainable processes with selective heterogeneous catalysts is of great significance.

The supported gold catalyst exhibited potential high activity and selectivity in this reaction, which proceeded under the moderate conditions [15-17]. However, the catalytic performances of gold catalysts were largely affected by various factors, such as the morphology of the gold $[4,23]$, the mean particle size [3,24,25], and the support effect [20,26-28], etc. Thus, clarifying the intrinsic origin of the catalytic reactivity related to the gold catalysts is crucial. In addition, the preparation of the gold catalysts with monodisperse size is difficult because the gold particles are prone to aggregating and growing into bigger ones in the preparation and reaction processes due to the high surface energy of small nanoparticles $[29,30]$. Hence, preparing the gold catalysts with good performance and establishing their structure-performance relationship are challenging.

The atomically precise gold nanoclusters (NCs) were regarded as good precursors for the preparation of supported gold catalysts. It is appropriate to study the support-dependent properties due to their well-defined structures and excellent size control [31-39]. Among them, the mercaptan-protected $\mathrm{Au}_{25}(\mathrm{SR})_{18} \mathrm{NCs}$ were supposed to be the most stable cluster and the smallest magic cluster, which was being used as the model catalysts for diverse reactions [31-39]. To date, the supported $\mathrm{Au}_{25} \mathrm{NCs}$ have been utilized in numbers of oxidation and hydrogenation reactions, such as the CO oxidation [31,32], the styrene oxidation [33,34], the Ullmann coupling reaction [35], the reduction of nitrophenol [36], the selective hydrogenation of functionalized nitroarenes [37,38], the selective hydrogenation of $\alpha, \beta$-unsaturated ketones and aldehydes [39], etc. In these reactions, the supported $\mathrm{Au}_{25} \mathrm{NCs}$ on specific supports displayed good performance. Thus, to make it clear how the supports affect the performances is crucial for understanding the behavior of the gold catalysts.

On supported gold catalysts, it was generally considered that the support effect could greatly influence the catalytic performances of the catalysts by interacting with the gold particles $[6,15,34]$, providing the surface defect sites [4,31], modifying the electronic state of gold [19,34], and supplying the acid-base sites for the reaction [20,38]. However, to investigate the above factors, it is critical to synthesize the gold particles with similar mean particle sizes. In previous works, the aerobic oxidation of benzyl alcohol to benzaldehyde over the supported gold catalysts was often conducted on the traditional gold nanoparticles, of which the controllable synthesis of the small gold particles with the same method on different supports was very hard $[15,19,20,25]$. In addition, the presence of the basic additives such as $\mathrm{KOH}$ and $\mathrm{K}_{2} \mathrm{CO}_{3}$ greatly limited its further study since it was not easy to identify the key causes contributing to the reactivity.

In this work, a series of gold catalysts on different supports including the MgAl hydrotalcite (HT), $\mathrm{ZnAl}-\mathrm{HT}, \mathrm{MgO}, \mathrm{ZnO}, \mathrm{Al}_{2} \mathrm{O}_{3}$, and $\mathrm{SiO}_{2}$ were prepared, using the atomically precise $\mathrm{Au}_{25} \mathrm{NCs}$ as the precursor of gold. For comparison, the gold catalysts supported on the same MgAl-HT support were also prepared by different methods. These catalysts exhibited distinct catalytic activities in aerobic 
oxidation reaction of benzyl alcohol without the addition of any inorganic base. The $\mathrm{N}_{2}$ physical adsorption, X-ray diffraction (XRD), UV-vis, transmission electron microscopy (TEM), high resolution TEM, X-ray photoelectron spectra (XPS), and $\mathrm{NH}_{3} / \mathrm{CO}_{2} / \mathrm{O}_{2}$-temperature programmed desorption (TPD) were utilized to evaluate the structural property, the electronic state, and the acid-base property of the catalysts. The relationships about the catalytic performances with the structural, electronic, and acid-base properties were then discussed in the following work.

\section{Results and Discussion}

\subsection{Characterizations of Supported $A u_{25}$ Nanoclusters}

A deep understanding of the size effect and support effect would lead to an improvement of supported gold catalysts. To this end, it is desirable to separate these factors. In this work, the atomically precise $\mathrm{Au}_{25} \mathrm{NCs}$ were synthesized by the $\mathrm{NaOH}$-mediated $\mathrm{NaBH}_{4}$ reduction method according to our previous work $[37,38]$. Thus, the effect of the preparation method or size effect might be ignored in some aspects. Meanwhile, different types of supports including the MgAl-HT, $\mathrm{ZnAl}-\mathrm{HT}, \mathrm{MgO}, \mathrm{ZnO}$, $\mathrm{Al}_{2} \mathrm{O}_{3}$, and $\mathrm{SiO}_{2}$ were selected to synthesize the supported $\mathrm{Au}_{25} \mathrm{NCs}$. Since the materials present the inert oxides supports and possess different acid-base properties [19,20,25]. In addition, the gold catalysts with different sizes were prepared by varying the loadings or different methods. Thus, the size effect could be discussed on the same supports. All of the samples before use were calcined at $300^{\circ} \mathrm{C}$ in air atmosphere to remove the protectant, which might be poisonous for the catalysts [32,34]. Inductively coupled plasma atomic emission spectroscopy (ICP-AES) measurement was employed to test the actual loadings of gold in the differently supported $\mathrm{Au}_{25} \mathrm{NCs}$ (Table 1). They displayed a similar gold content between $0.4-0.7 \%$, consistent with the theoretical value $(0.5 \%)$. The actual values will be taken into account in calculation of the reaction rates afterwards.

Table 1. Textural properties of different supported gold catalysts.

\begin{tabular}{|c|c|c|c|c|c|c|}
\hline Entry & Sample & $\begin{array}{c}\text { Loadings of } \\
\mathrm{Au}(\%)^{\mathrm{a}}\end{array}$ & $S_{\text {BET }}\left(\mathrm{m}^{2} / \mathrm{g}\right)^{b}$ & $\begin{array}{l}V_{\text {mesopore }} \\
\left(\mathrm{cm}^{3} / \mathrm{g}\right)^{b}\end{array}$ & $D_{\text {pore }}(n m)^{b}$ & Size $(\mathrm{nm})^{c}$ \\
\hline 1 & $\mathrm{Au}_{25} / \mathrm{MgAl}-300$ & 0.5 & 131.2 & 0.6 & 15.5 & 3.1 \\
\hline 2 & $\mathrm{Au}_{25} / \mathrm{ZnAl}-300$ & 0.7 & 112.6 & 0.3 & 26.4 & 2.7 \\
\hline 3 & $\mathrm{Au}_{25} / \mathrm{MgO}-300$ & 0.5 & 10.1 & 0.03 & 27.3 & 2.6 \\
\hline 4 & $\mathrm{Au}_{25} / \mathrm{ZnO}-300$ & 0.4 & 4.0 & 0.02 & 27.4 & 2.7 \\
\hline 5 & $\mathrm{Au}_{25} / \mathrm{Al}_{2} \mathrm{O}_{3}-300$ & 0.4 & 235.4 & 0.3 & 6.5 & 2.8 \\
\hline 6 & $\mathrm{Au}_{25} / \mathrm{SiO}_{2}-300$ & 0.4 & 367.1 & 0.7 & 7.0 & 5.9 \\
\hline
\end{tabular}

a The actual loadings of gold were evaluated by ICP-AES measurement; ${ }^{b}$ The specific surface area and pore structure were evaluated by $\mathrm{N}_{2}$-physical adsorption-desorption test; ${ }^{\mathrm{c}}$ The mean particle sizes were calculated from TEM measurement.

The pore structure parameters such as the specific area $\left(\mathrm{S}_{\mathrm{BET}}\right)$, the pore volume $\left(\mathrm{V}_{\text {mesopore }}\right)$, and the pore diameter $\left(\mathrm{D}_{\text {pore }}\right)$ were evaluated by an $\mathrm{N}_{2}$-physical adsorption-desorption test. The results were showed in Figure 1 and Table 1 . From the results, the $\mathrm{Au}_{25} / \mathrm{MgO}-300$ and $\mathrm{Au}_{25} / \mathrm{ZnO}-300$ catalysts showed the adsorption/desorption isotherms almost overlapping, which suggests that the specific area and the pore volume are too small. In addition, the isotherms of the $\mathrm{Au}_{25} / \mathrm{MgAl}-300$ and $\mathrm{Au}_{25} / \mathrm{ZnAl}-300$ catalysts were horizontal and parallel to each other at lower $\mathrm{P} / \mathrm{P}_{0}$ ratios, and they arise steeply when the relative pressures approach 1 . Thus, the $\mathrm{Au}_{25} / \mathrm{MgAl}-300$ and $\mathrm{Au}_{25} / \mathrm{ZnAl}-300$ catalysts might possess slit-shaped pores resulted from the layered structure [40]. Moreover, the $\mathrm{Au}_{25} / \mathrm{Al}_{2} \mathrm{O}_{3}-300$ and $\mathrm{Au}_{25} / \mathrm{SiO}_{2}-300$ catalysts displayed a typical shape of type IV isotherm according to the International Union of Pure and Applied Chemistry (IUPAC) classification [41,42], with a sharp step at intermediate relative pressures. This type of isotherm indicated the presence of textural mesopores [42]. 

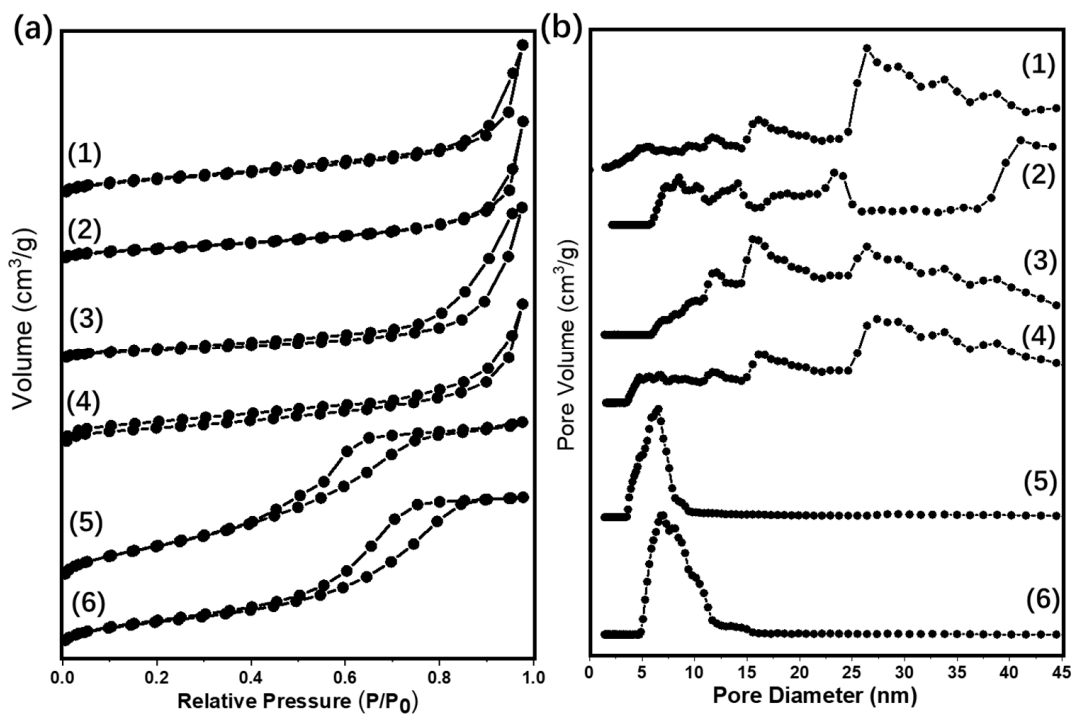

Figure 1. (a) $\mathrm{N}_{2}$ adsorption/desorption isotherms and (b) pore size distributions of different supported gold catalysts: (1) $\mathrm{Au}_{25} / \mathrm{ZnAl}-300$; (2) $\mathrm{Au}_{25} / \mathrm{ZnO}-300$; (3) $\mathrm{Au}_{25} / \mathrm{MgAl}-300$; (4) $\mathrm{Au}_{25} / \mathrm{MgO}-300$; (5) $\mathrm{Au}_{25} / \mathrm{Al}_{2} \mathrm{O}_{3}-300$; (6) $\mathrm{Au}_{25} / \mathrm{SiO}_{2}-300$.

Table 1 displayed the values of specific area, the pore volume, and the pore diameter. Over the different supported gold catalysts, the $\mathrm{S}_{\mathrm{BET}}$ decreased as the following order: $\mathrm{Au}_{25} / \mathrm{SiO}_{2}-300>$ $\mathrm{Au}_{25} / \mathrm{Al}_{2} \mathrm{O}_{3}-300>\mathrm{Au}_{25} / \mathrm{MgAl}-300>\mathrm{Au}_{25} / \mathrm{ZnAl}-300>\mathrm{Au}_{25} / \mathrm{MgO}-300>\mathrm{Au}_{25} / \mathrm{ZnO}-300$. To be noted, the $\mathrm{SiO}_{2}$ supported gold catalyst possessed a comparable high specific area of $367.1 \mathrm{~m}^{2} / \mathrm{g}$ due to the functionalization of 3-aminopropyltriethoxysilane (APTES) to the surface. Otherwise, the $\mathrm{Au}_{25} \mathrm{NCs}$ was hard to infuse into the support and the loadings of gold were below $0.1 \%$. The $\mathrm{Au}_{25} / \mathrm{Al}_{2} \mathrm{O}_{3}-300$ catalyst had the second largest specific area of $235.4 \mathrm{~m}^{2} / \mathrm{g}$, with similar pore diameter of $\mathrm{Au}_{25} / \mathrm{SiO}_{2}-300$. This might be beneficial for dispersion of the gold and inhibiting the growth and agglomeration of gold species on the surface [43]. MgAl-hydrotalcite (HT) and ZnAl-HT supported gold NCs had a moderate $S_{\mathrm{BET}}\left(131.2\right.$ and $\left.112.6 \mathrm{~m}^{2} / \mathrm{g}\right)$ and wide distribution of pore diameter due to their layer structures. In addition, the $\mathrm{Au}_{25} / \mathrm{MgO}-300$ and $\mathrm{Au}_{25} / \mathrm{ZnO}-300$ catalysts had very low specific area of 10.1 and $4.0 \mathrm{~m}^{2} / \mathrm{g}$, respectively, with the small pore volume and wide distribution of pore diameter. Notably, the pore structures of the bare oxide supports were almost the same as the corresponding gold catalysts (Figure S1 and Table S1), which display the intact structure of the oxides after the loading of gold. The mean particle sizes of gold were then calculated from the TEM measurement, which would be discussed in the next paragraph.

The structural properties of the supported $\mathrm{Au}_{25} \mathrm{NCs}$ catalysts and the corresponding supports were evaluated from X-ray diffraction (XRD) measurement (Figure 2 and Figure S1). From the XRD patterns, all the catalysts and supports after calcination displayed the specific structure of the precursor or metal oxides. This means that the preparation of six different supported gold catalysts was successful. As showed in Figure $2 a$, the diffraction peaks could be identified from the order of the $\mathrm{ZnO}$ phase, which was similar with the structure of $\mathrm{ZnO}$ in Figure $2 \mathrm{~b}$. It implied that the ZnAl-hydrotalcite had transformed into the atomic mixed oxide after calcination. In addition, the same phase between the supports and the catalysts in Figure 2 and Figure S2 suggested the adsorption of gold into the supports had not changed the structure. Figure $2 \mathrm{c}$ showed the diffraction peaks of MgAl-hydrotalcite and $\mathrm{MgO}$. Based on the previous study [15], the calcination temperature of $300{ }^{\circ} \mathrm{C}$ might not be enough to transform the hydrotalcite into the complete magnesium oxides, while, at this temperature, the $\mathrm{MgAl}$-hydrotalcite supported gold catalysts could display good performances in different reactions $[15,38]$. In addition, the gold catalysts calcined at the same temperature was imperative for comparison of the different gold catalysts, since the size distribution largely depends on the heat treatment temperature [32,37]. Subsequently, Figure $2 \mathrm{~d}$ shows the intact phase structure of 
$\mathrm{MgO}$, which maintained the originate state of the supports. The diffraction peaks in Figure 2e could be ascribed to the structure of $\gamma-\mathrm{Al}_{2} \mathrm{O}_{3}$ [21]. Due to the low temperature of thermal decomposition, the precursor of $\mathrm{Al}(\mathrm{OH})_{3}$ dehydrated and transformed to the $\gamma-\mathrm{Al}_{2} \mathrm{O}_{3}$ instead of the $\alpha-\mathrm{Al}_{2} \mathrm{O}_{3}$ [21], the latter was generally utilized for the corundum. Figure $2 \mathrm{f}$ displayed a broad peak at $22.5^{\circ}$, which was assigned to the amorphous $\mathrm{SiO}_{2}$ [44]. In addition, no diffraction peaks of gold appeared on all the catalysts. This was caused by the low loadings of gold.
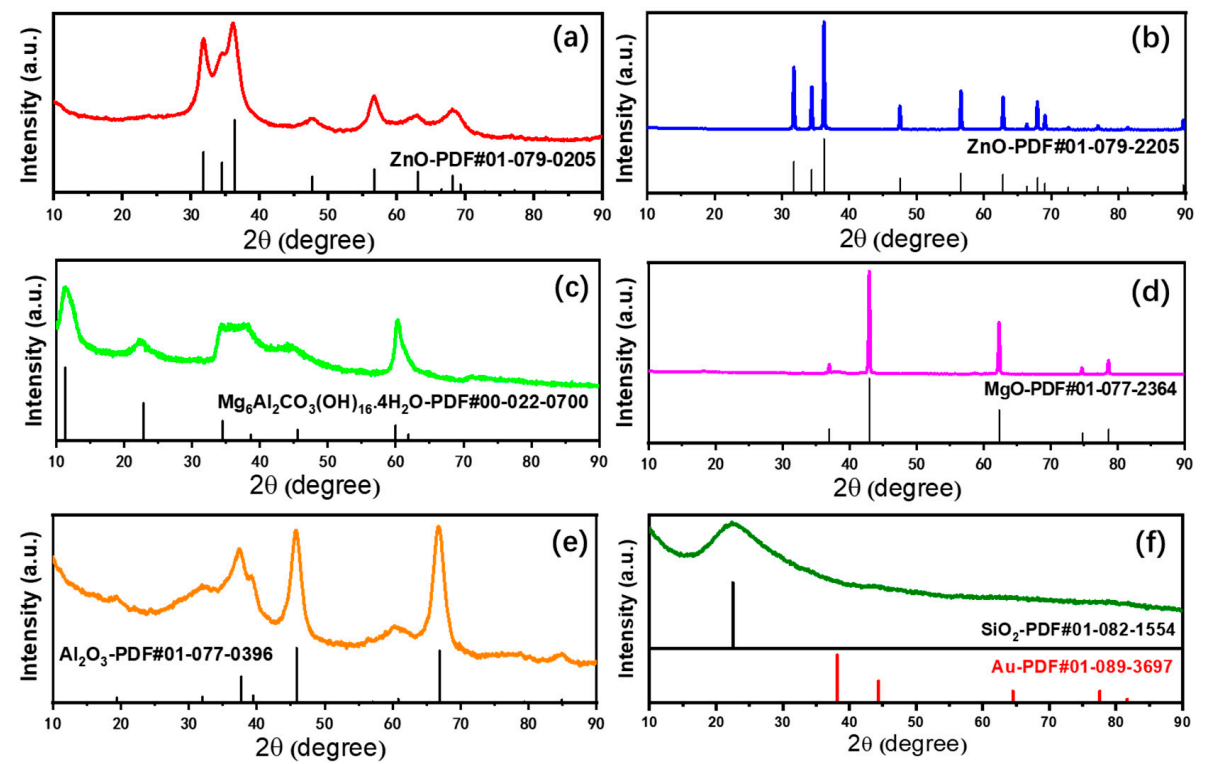

Figure 2. X-ray diffraction patterns of different supported gold catalysts; (a) $\mathrm{Au}_{25} / \mathrm{ZnAl}-300$;

(b) $\mathrm{Au}_{25} / \mathrm{ZnO}-300 ;$ (c) $\mathrm{Au}_{25} / \mathrm{MgAl}-300$; (d) $\mathrm{Au}_{25} / \mathrm{MgO}-300$; (e) $\mathrm{Au}_{25} / \mathrm{Al}_{2} \mathrm{O}_{3}-300$; (f) $\mathrm{Au}_{25} / \mathrm{SiO}_{2}-300$.

UV-vis spectra could also display some information about size distribution of the Au catalyst [37,45]. For the six supported gold catalysts in this work the UV-visible diffuse reflectance spectra were recorded from 200-800 nm at solid mode with the $\mathrm{BaSO}_{4}$ as the reference (Figure 3). Obviously, there were broad absorption bands located at $520-550 \mathrm{~nm}$ on all the catalysts, which is characteristic of the plasmon resonance band of gold nanoparticles [45]. As seen from the spectra, all of the bands had a large half peak width and no sharp peaks appeared in the spectra, which means that the gold particles were not aggregating [37].

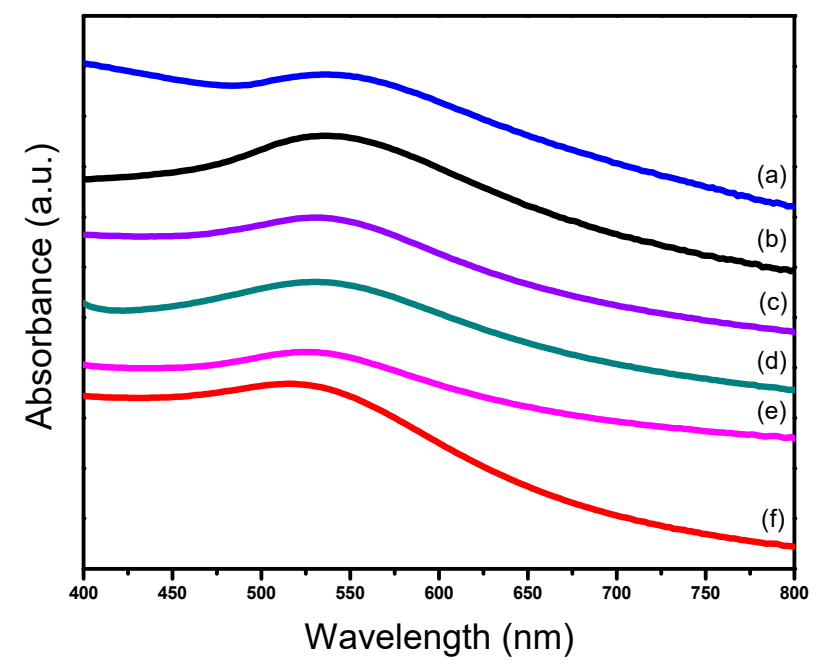

Figure 3. UV-vis spectra of different supported gold catalysts; (a) $\mathrm{Au}_{25} / \mathrm{SiO}_{2}-300$; (b) $\mathrm{Au}_{25} / \mathrm{MgAl}-300$; (c) $\mathrm{Au}_{25} / \mathrm{MgO}-300 ;$ (d) $\mathrm{Au}_{25} / \mathrm{ZnAl}-300 ;\left(\right.$ e) $\mathrm{Au}_{25} / \mathrm{ZnO}-300$; (f) $\mathrm{Au}_{25} / \mathrm{Al}_{2} \mathrm{O}_{3}-300$. 
The TEM images and size distribution histograms of supported $\mathrm{Au}_{25} \mathrm{NCs}$ catalysts after heat treatment were shown in Figure 4. The dark spots presented in images were defined as the gold particles. From the electronic photos, the gold particles were highly dispersed on various supports. The average particles sizes of gold were within $3 \mathrm{~nm}$ with narrow distributions in most of the catalysts, which are $3.0 \pm 1.2,2.6 \pm 0.9,2.7 \pm 0.7,2.7 \pm 1.2,2.7 \pm 1.1 \mathrm{~nm}$ for the $\mathrm{Au}_{25} / \mathrm{MgAl}-300$ (Figure 4a), $\mathrm{Au}_{25} / \mathrm{MgO}-300$ (Figure 4b), $\mathrm{Au}_{25} / \mathrm{ZnAl}-300$ (Figure 4c), $\mathrm{Au}_{25} / \mathrm{ZnO}-300$ (Figure 4d) and $\mathrm{Au}_{25} / \mathrm{Al}_{2} \mathrm{O}_{3}-300$ (Figure 4e) catalysts, respectively. It meant the $\mathrm{Au}_{25} \mathrm{NCs}$ could be stabilized on MgAl-HT, ZnAl-HT, $\mathrm{MgO}, \mathrm{ZnO}$, and $\mathrm{Al}_{2} \mathrm{O}_{3}$ supports, whereas the mean particle size of the $\mathrm{Au}_{25} / \mathrm{SiO}_{2}-300$ catalyst was about two times larger than that on others, on which the particle size of gold was $5.9 \pm 1.7 \mathrm{~nm}$ (Figure $4 \mathrm{f}$ ). The reason might be caused by the weak interaction between gold and the $\mathrm{SiO}_{2}$. In this situation, the gold NCs might grow to be the bigger ones on the surface without the anchor of the carrier. This led to an increased particle size of gold in $\mathrm{Au}_{25} / \mathrm{SiO}_{2}-300$. The supposition could be verified by high resolution TEM (HRTEM). The representative electronic images were displayed in Figure S3. From the photos, the gold particles on the $\mathrm{Au}_{25} / \mathrm{SiO}_{2}-300$ catalyst showed the round shape, yet, over the other catalysts, the gold particles were hexagonal or polygonal. The phenomenon revealed the fact that the gold particles weakly interacted with the supports would lead to a smooth interface, whereas the gold strongly interacted with the supports would result in an irregular shape [33,46]. Thus, the gold and the supports could share more terraces and steps, which facilitated the anchoring of gold on the surface $[46,47]$. Furthermore, by analyzing the direction of lattice fringes, there was obvious tropism between gold and the supports (Figure S3a-e), which further suggests the possibility of the strong interaction between gold and the support [37,38].

It is worth noting that the low resolution TEM on the low contrast applied in this study could not reveal the small gold particles on the surface. Thus, some small gold particles were not included in calculation of the mean particle size. It might be the reason why the mean particle sizes in this work were larger than that in our previous study $[37,38]$, even though the loadings of gold were somewhat different. Further study about high resolution TEM or HAADF-STEM was needed to give more precise value. Still, we demonstrated that the preparation method applied in this work was suitable for the synthesis of gold catalysts with controllable sizes. The gold particles were uniformly distributed on different supports such as $\mathrm{MgAl}-\mathrm{HT}, \mathrm{ZnAl}-\mathrm{HT}, \mathrm{MgO}, \mathrm{ZnO}$, and $\mathrm{Al}_{2} \mathrm{O}_{3}$. In addition, it can exclude the influence of the preparation method on the study of the gold catalysts.

The XPS analyses were a good characterization to test the electronic state of the catalysts. To shed light on the electronic effect, the valent state of gold and the other elements were analyzed. Thus, one can identify whether the interaction between gold and the support existed in the catalysts. In general, the interaction between gold and the support was reported to make an essential difference in catalytic reactions $[33,34]$. Thus, the supports could modify the electronic properties of gold by this method, and their performances could be adjusted.

In this study, the XPS spectra of Au $4 \mathrm{f}$ were presented in Figure 5. All catalysts showed the characteristic bands of $\mathrm{Au} 4 \mathrm{f} 5 / 2$ and $\mathrm{Au} 4 \mathrm{f} 7 / 5$, and their binding energies of $\mathrm{Au} 4 \mathrm{f} 7 / 2$ lines were observed at 83.1, 83.2, 83.2, 83.7, 83.6, and $83.9 \mathrm{eV}$ for $\mathrm{Au}_{25} / \mathrm{MgAl}-300, \mathrm{Au}_{25} / \mathrm{MgO}-300, \mathrm{Au}_{25} / \mathrm{ZnAl}-300$, $\mathrm{Au}_{25} / \mathrm{ZnO}-300, \mathrm{Au}_{25} / \mathrm{Al}_{2} \mathrm{O}_{3}-300$, and $\mathrm{Au}_{25} / \mathrm{SiO}_{2}-300$ catalysts, respectively. Since the metallic gold of $\mathrm{Au}(0) 4 \mathrm{f} 7 / 2$ line was generally reported at $84.0 \mathrm{eV}$ [15,33], and the valent state of gold in $\mathrm{Au}_{25} / \mathrm{SiO}_{2}-300$ catalyst was $83.9 \mathrm{eV}$; thus, accordingly, the gold on the $\mathrm{Au}_{25} / \mathrm{SiO}_{2}-300$ catalyst was close to $\mathrm{Au}(0)$. Namely, the interaction between gold with the $\mathrm{SiO}_{2}$ was week. This result was very consistent with the previous HRTEM results—-that the weak interaction led to the round shape of gold on the $\mathrm{SiO}_{2}$ support (Figure S3f). 

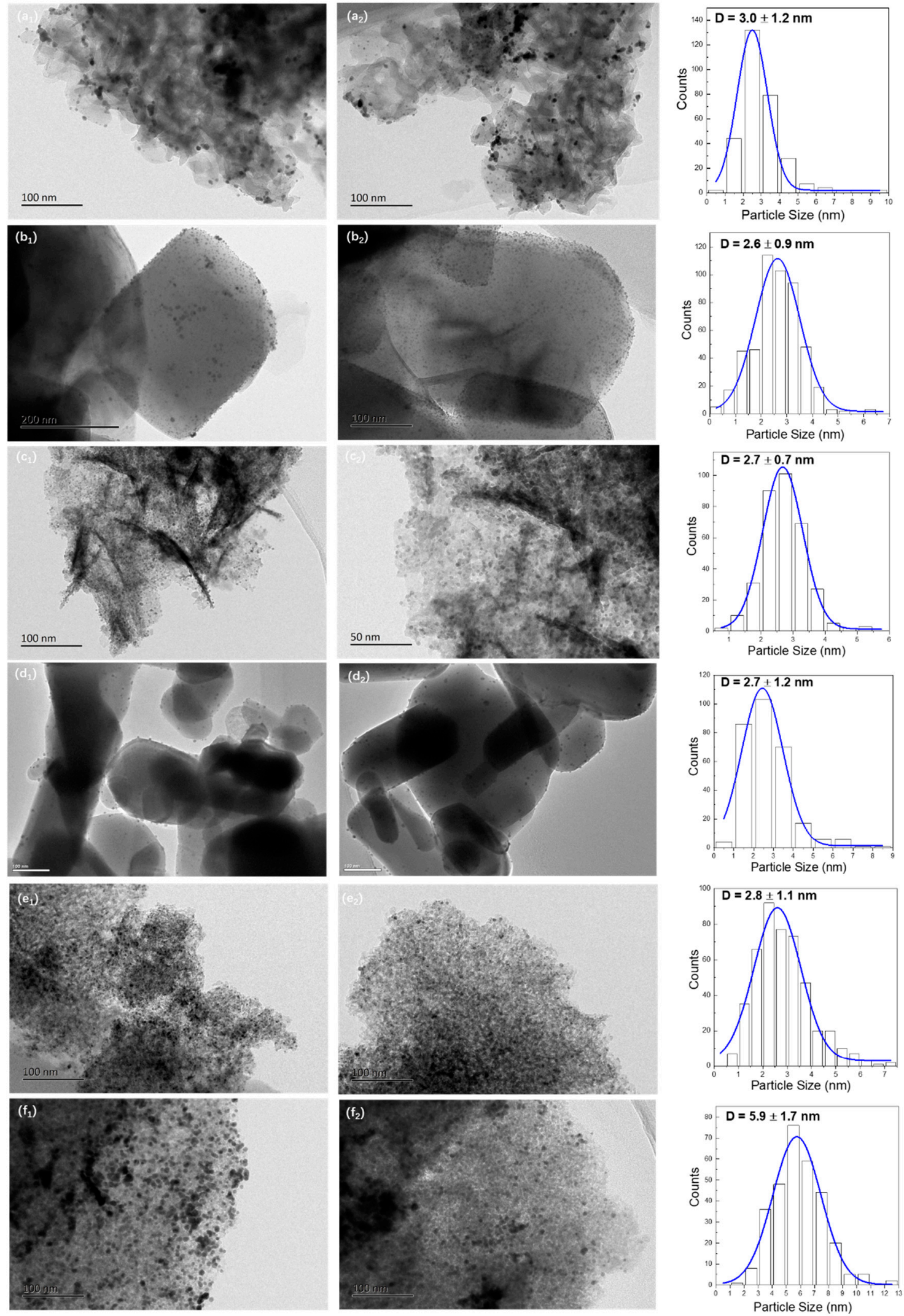

Figure 4. TEM images and size distribution histograms of different supported gold catalysts; (a1-2) $\mathrm{Au}_{25} / \mathrm{MgAl}-300$; (b $\left.\mathbf{b}_{1-2}\right) \mathrm{Au}_{25} / \mathrm{MgO}-300 ;\left(\mathbf{c}_{1-2}\right) \mathrm{Au}_{25} / \mathrm{ZnAl}-300 ;\left(\mathbf{d}_{1-2}\right) \mathrm{Au}_{25} / \mathrm{ZnO}-300 ;\left(\mathbf{e}_{1-2}\right)$ $\mathrm{Au}_{25} / \mathrm{Al}_{2} \mathrm{O}_{3}-300 ;\left(\mathbf{f}_{1-2}\right) \mathrm{Au}_{25} / \mathrm{SiO}_{2}-300$. 

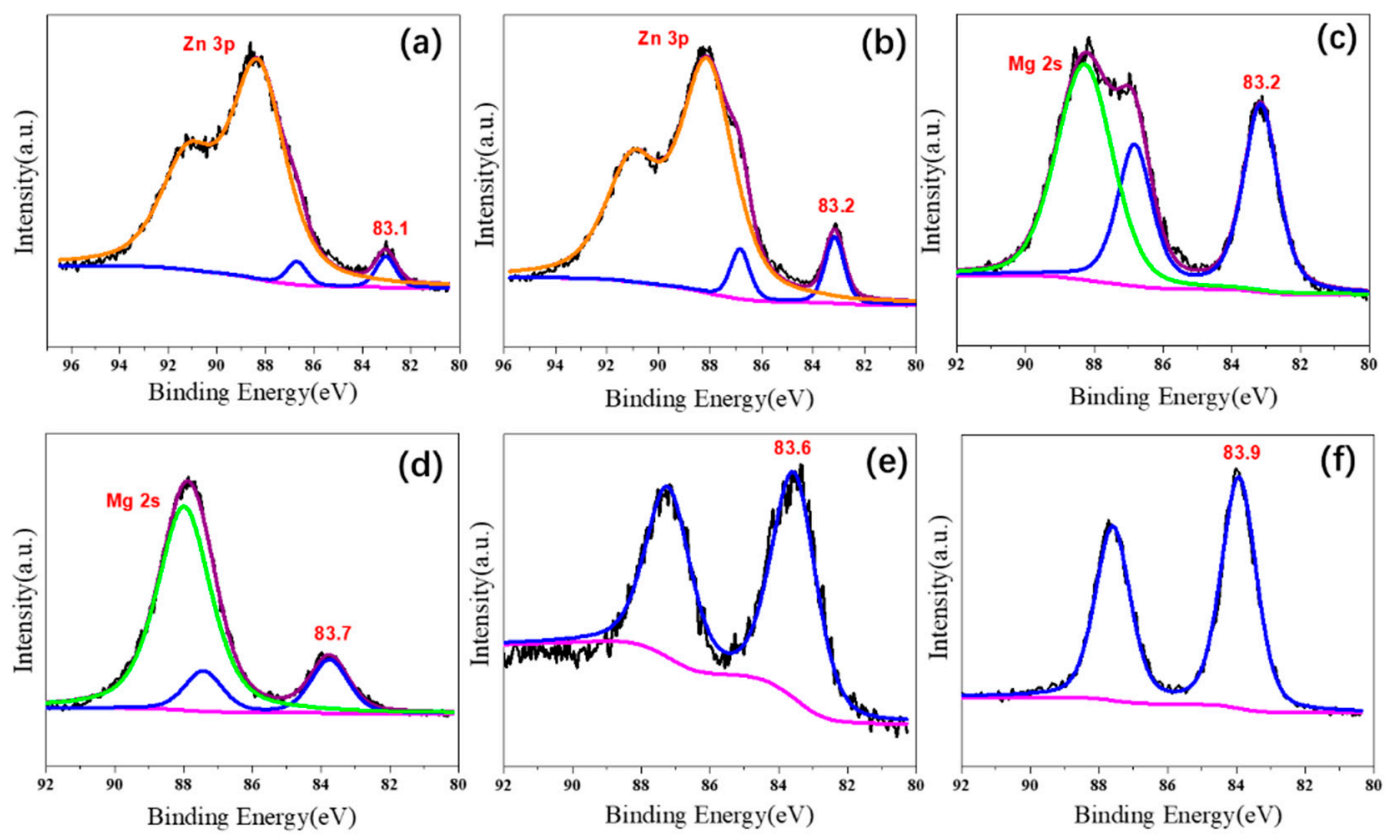

Figure 5. X-ray photoelectron spectra of $\mathrm{Au} 4 \mathrm{f}$ on different supported gold catalysts; (a) $\mathrm{Au}_{25} / \mathrm{ZnAl}-300$; (b) $\mathrm{Au}_{25} / \mathrm{ZnO}-300$; (c) $\mathrm{Au}_{25} / \mathrm{MgAl}-300$; (d) $\mathrm{Au}_{25} / \mathrm{MgO}-300$; (e) $\mathrm{Au}_{25} / \mathrm{Al}_{2} \mathrm{O}_{3}-300$; (f) $\mathrm{Au}_{25} / \mathrm{SiO}_{2}-300$.

However, the gold in $\mathrm{Au}_{25} / \mathrm{Al}_{2} \mathrm{O}_{3}-300$ and $\mathrm{Au}_{25} / \mathrm{MgO}-300$ catalysts showed negative valent state in comparison with the $\mathrm{Au}_{25} / \mathrm{SiO}_{2}-300$, of which the binding energies were 83.7 and $83.6 \mathrm{eV}$, respectively. In particular, the valent states were even lower in $\mathrm{Au}_{25} / \mathrm{MgAl}-300, \mathrm{Au}_{25} / \mathrm{ZnAl}-300$, and $\mathrm{Au}_{25} / \mathrm{ZnO}-300$ catalysts. The binding energies were 83.2, 83.1, and $83.2 \mathrm{eV}$ for $\mathrm{Au} 4 \mathrm{f} 7 / 2$ lines, respectively. This strongly suggests a stronger interaction between gold and the supports existed in these systems, where the electron-transfer could occur between the two entities. The XPS spectra of $\mathrm{O} 1 \mathrm{~s}$ were also provided in Figure S4. For example, two peaks located at 530.0 and $531.4 \mathrm{eV}$ in $\mathrm{Au}_{25} / \mathrm{ZnAl}-300$ and $\mathrm{Au}_{25} / \mathrm{ZnO}-300$ catalysts could be ascribed to $\mathrm{O}^{2-}$ ions on the wurtzite structure of hexagonal $\mathrm{Zn}^{2+}$ ion array and the $\mathrm{O}^{2-}$ ions in oxygen-deficient regions within the $\mathrm{ZnO}$ matrix, respectively $[48,49]$. It indicates the different valent states and structural features of the supports that appeared in these catalysts.

The basic and acid properties were evaluated by $\mathrm{CO}_{2}$ and $\mathrm{NH}_{3}$ pulse adsorption followed by TPD measurements. The results were listed in Figures 6 and 7 and Table S2. The total basicity and acidity could be calculated by the amounts of pulse adsorption (Table S2) [50,51]. From the aspect of basicity, the $\mathrm{Au}_{25} / \mathrm{MgAl}-300$ catalyst exhibited the maximum basic sites, with the adsorbed $\mathrm{CO}_{2}$ of $1130 \mu \mathrm{mol} / \mathrm{g}$. The following order was: $\mathrm{Au}_{25} / \mathrm{Al}_{2} \mathrm{O}_{3}-300(460 \mu \mathrm{mol} / \mathrm{g})>\mathrm{Au}_{25} / \mathrm{ZnAl}-300(310 \mu \mathrm{mol} / \mathrm{g})>$ $\mathrm{Au}_{25} / \mathrm{MgO}-300(90 \mu \mathrm{mol} / \mathrm{g})>\mathrm{Au}_{25} / \mathrm{SiO}_{2}-300(20 \mu \mathrm{mol} / \mathrm{g})>\mathrm{Au}_{25} / \mathrm{ZnO}-300(10 \mu \mathrm{mol} / \mathrm{g})$. In addition, the profiles of $\mathrm{CO}_{2}$-TPD experiment about the strength of base sites over the different supported gold catalysts were showed in Figure 6. From the results, the $\mathrm{Au}_{25} / \mathrm{MgAl}-300$ catalyst presented one obvious peak at $200-600{ }^{\circ} \mathrm{C}$, which was assigned to the medium base resulted from the $\mathrm{M}^{2+}-\mathrm{O}^{2-}$ pairs $[20,25]$. The $\mathrm{Au}_{25} / \mathrm{Al}_{2} \mathrm{O}_{3}-300$ catalyst showed a broad band at $200-800{ }^{\circ} \mathrm{C}$, which indicated the weak sites, medium sites, and strong sites of the base might be coexisting in the catalyst. The $\mathrm{Au}_{25} / \mathrm{ZnAl}-300$ and $\mathrm{Au}_{25} / \mathrm{MgO}-300$ catalysts displayed a peak at $200-400{ }^{\circ} \mathrm{C}$, while the $\mathrm{Au}_{25} / \mathrm{SiO}_{2}-300$ and $\mathrm{Au}_{25} / \mathrm{ZnO}-300$ catalysts showed almost no basicity. To be noted, the $\mathrm{ZnO}$ was generally considered to be a basic oxide and had been used in several base-catalyzed processes [52,53]. However, some others presented no or low basicity of $\mathrm{ZnO}$ in different systems [54-56], which agree well with our work. We speculated that the low basicity of $\mathrm{ZnO}$ in this study might be result from the heat pretreatment at $500{ }^{\circ} \mathrm{C}$ before use, since the basic sites of zinc oxide might be decreased at elevated temperatures $[55,56]$. 

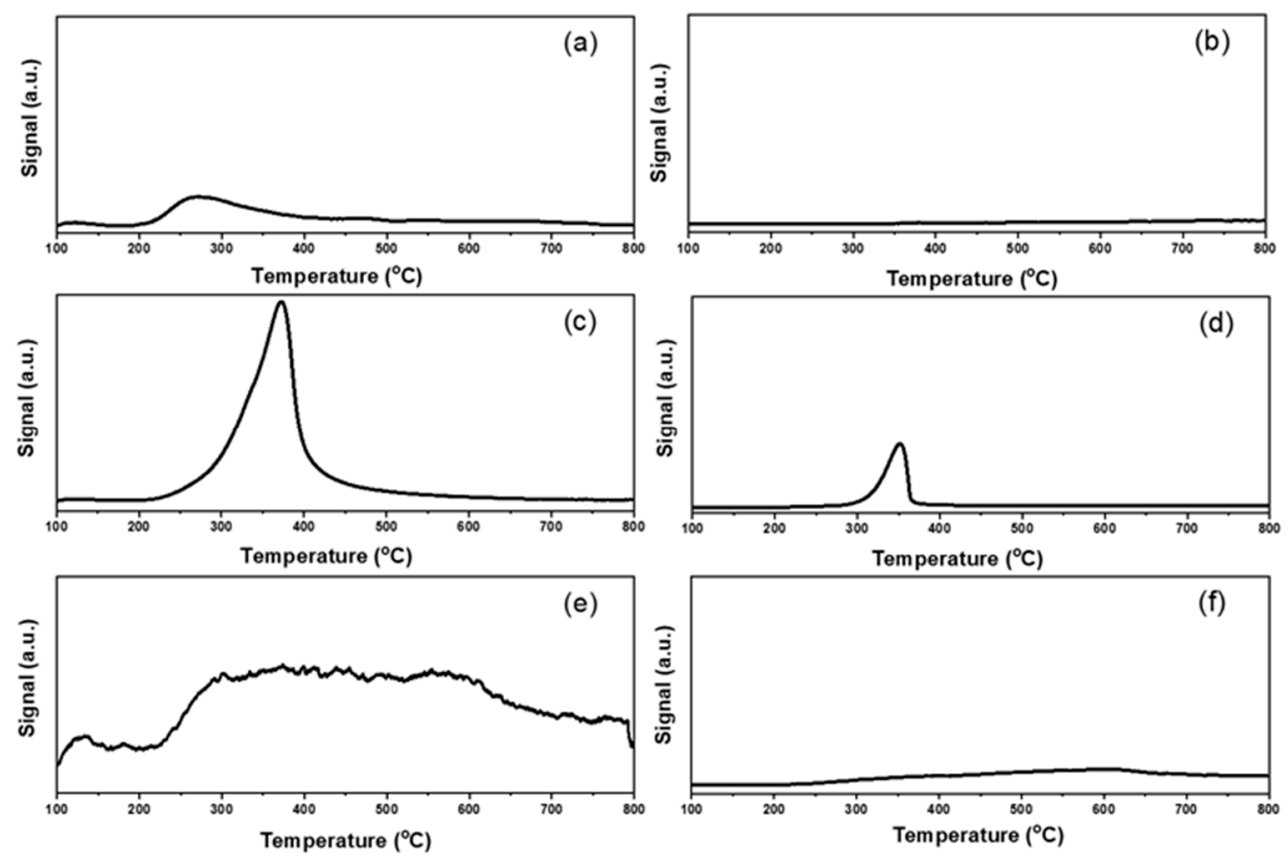

Figure 6. $\mathrm{CO}_{2}$-temperature programmed desorption profiles of different supported gold catalysts: (a) $\mathrm{Au}_{25} / \mathrm{ZnAl}-300$; (b) $\mathrm{Au}_{25} / \mathrm{ZnO}-300$; (c) $\mathrm{Au}_{25} / \mathrm{MgAl}-300$; (d) $\mathrm{Au}_{25} / \mathrm{MgO}-300$; (e) $\mathrm{Au}_{25} / \mathrm{Al}_{2} \mathrm{O}_{3}-300$; (f) $\mathrm{Au}_{25} / \mathrm{SiO}_{2}-300$.
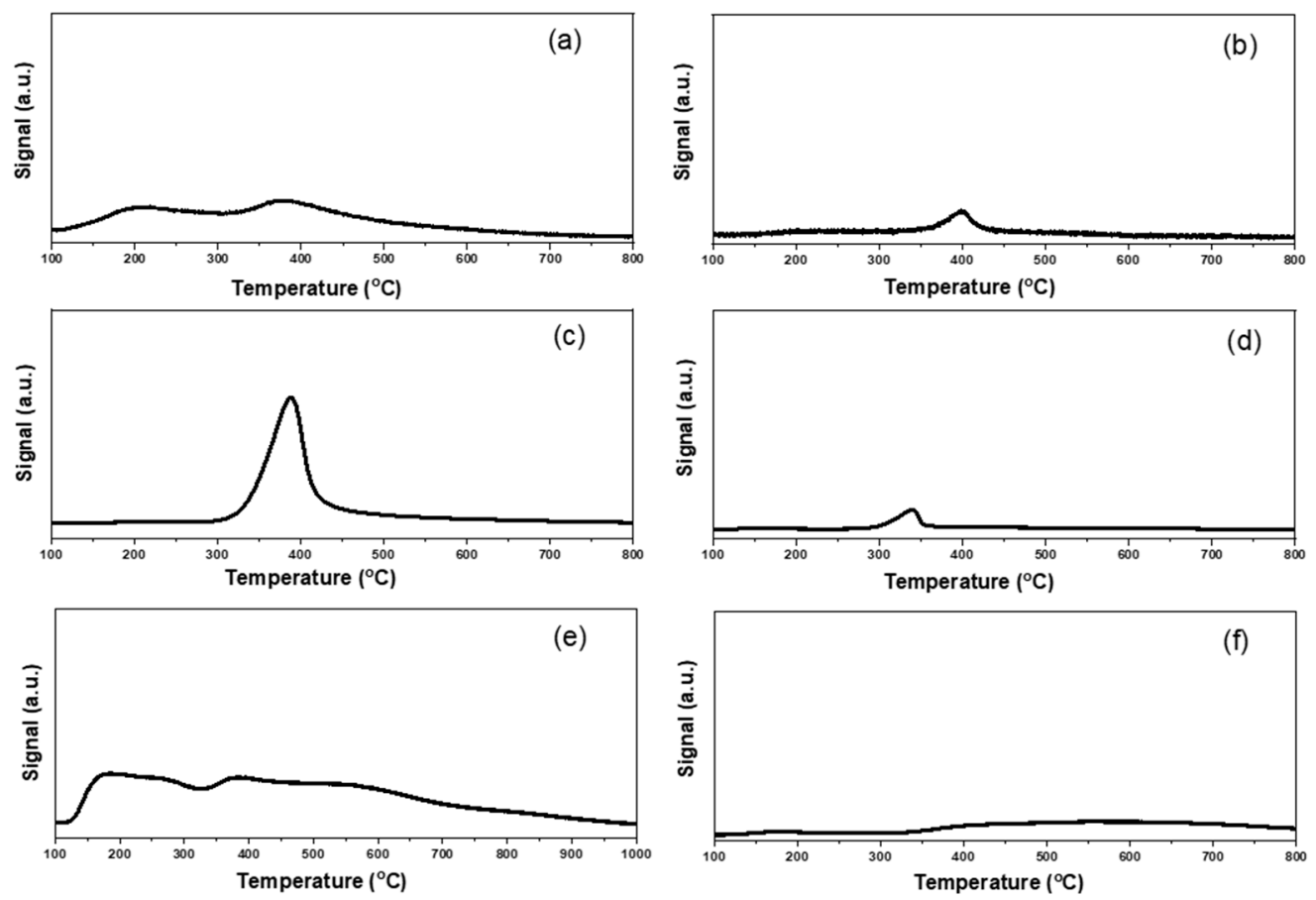

Figure 7. $\mathrm{NH}_{3-}$ TPD profiles of different supported gold catalysts: (a) $\mathrm{Au}_{25} / \mathrm{ZnAl}-300$; (b) $\mathrm{Au}_{25} / \mathrm{ZnO}-300$; (c) $\mathrm{Au}_{25} / \mathrm{MgAl}-300 ;$ (d) $\mathrm{Au}_{25} / \mathrm{MgO}-300 ;$ (e) $\mathrm{Au}_{25} / \mathrm{Al}_{2} \mathrm{O}_{3}-300$; (f) $\mathrm{Au}_{25} / \mathrm{SiO}_{2}-300$.

Similarly, the total acidity and $\mathrm{NH}_{3}$-TPD profiles were presented in Table $\mathrm{S} 2$ and Figure 7. From the results, the maximum acid amounts were exhibited in $\mathrm{Au}_{25} / \mathrm{Al}_{2} \mathrm{O}_{3}-300$ catalyst, with desorption temperature of $\mathrm{NH}_{3}$ from $120-900{ }^{\circ} \mathrm{C}$. The order of the total acidity was as follows: $\mathrm{Au}_{25} / \mathrm{Al}_{2} \mathrm{O}_{3}-300$ $(1020 \mu \mathrm{mol} / \mathrm{g})>\mathrm{Au}_{25} / \mathrm{MgAl}-300(960 \mu \mathrm{mol} / \mathrm{g})>\mathrm{Au}_{25} / \mathrm{SiO}_{2}-300(250 \mu \mathrm{mol} / \mathrm{g})>\mathrm{Au}_{25} / \mathrm{ZnAl}-300$ $(150 \mu \mathrm{mol} / \mathrm{g})>\mathrm{Au}_{25} / \mathrm{ZnO}-300(150 \mu \mathrm{mol} / \mathrm{g})>\mathrm{Au}_{25} / \mathrm{MgO}-300(100 \mu \mathrm{mol} / \mathrm{g})$. The strength of acid sites could also be classified into three groups, the weak sites, the medium sites, and strong sites [25,45]. 
Among them, the $\mathrm{Au}_{25} / \mathrm{Al}_{2} \mathrm{O}_{3}-300$ catalyst possessed the three kinds of acid sites. The $\mathrm{Au}_{25} / \mathrm{MgAl}-300$ catalyst displayed a strong desorption peak of $\mathrm{NH}_{3}$ at $300-500{ }^{\circ} \mathrm{C}$, which was assigned to the medium acid sites. The $\mathrm{Au}_{25} / \mathrm{SiO}_{2}-300$ catalyst showed a broad band at $350-800{ }^{\circ} \mathrm{C}$, which could be ascribed to the medium and strong acid sites. The $\mathrm{Au}_{25} / \mathrm{ZnO}-300, \mathrm{Au}_{25} / \mathrm{MgO}-300$ and $\mathrm{Au}_{25} / \mathrm{ZnAl}-300$ catalysts possessed weak and/or medium acid sites.

\subsection{The Catalytic Activities of Different Supported Gold Catalysts}

The aerobic oxidation of benzyl alcohol was evaluated to test the catalytic performance of the supported $\mathrm{Au}_{25} \mathrm{NCs}$ catalysts. The general reaction route was illustrated in Scheme 1. Firstly, the benzyl alcohol (BA) was oxidized to benzaldehyde (BZ). Then, the benzaldehyde could be oxidized to benzoic acid (BC). At the same time, BA could further react with BZ or BC under the certain conditions to form the benzyl benzoate $(\mathrm{BO})[20,46]$. Notably, the benzene and toluene were also probably the products from the reaction, which has been demonstrated in various previous works $[57,58]$.

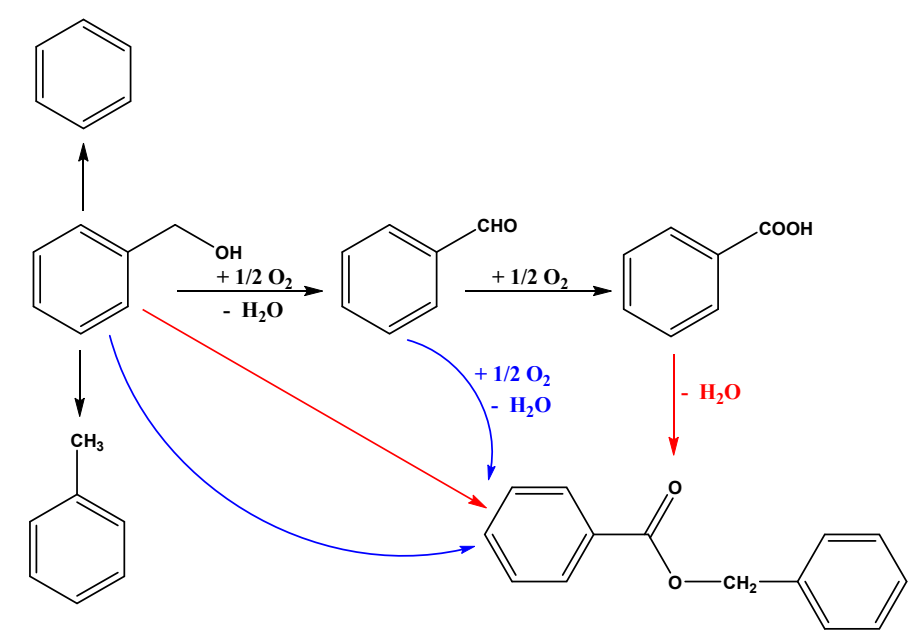

Scheme 1. The reaction route of aerobic oxidation of benzyl alcohol.

In this system, different supported gold catalysts for aerobic oxidation of BA were employed. The results were listed in Table 2. Notably, no any benzoic acid could be detected in the reaction mixture, and the benzyl benzoate appeared to be the only by-product, which might be formed by condensation of BA with BZ [57,59]. Obviously, the supported gold catalysts with different supports showed distinctive activities. Among them, the $\mathrm{Au}_{25} / \mathrm{MgAl}-300$ and $\mathrm{Au}_{25} / \mathrm{Al}_{2} \mathrm{O}_{3}-300$ catalysts exhibited the best performances (Table 2, entry 1,5), with the conversion of BA were $89.5 \%$ and $89.2 \%$, respectively, and the selectivities of $\mathrm{BZ}$ were $95.0 \%$ and $94.9 \%$, respectively. In addition, the Turnover Frequencies (TOF) of $\mathrm{Au}_{25} / \mathrm{MgAl}-300$ and $\mathrm{Au}_{25} / \mathrm{Al}_{2} \mathrm{O}_{3}-300$ catalysts were $993 \mathrm{~h}^{-1}$ and $1033 \mathrm{~h}^{-1}$, when the whole gold was considered in the reaction. However, according to the general acknowledgement, the gold atoms located at the surface were regarded as the active species $[3,24]$. Thus, it was reasonable to calculate the TOF values in consideration of the dispersion of gold. In order to precisely concatenate the intrinsic activity with the active sites, two groups of TOF values were provided in Table 2 to give a better correlation. However, the dispersion of gold was not easy to get from the experiment. Hence, it was estimated by the empirical equation of $1 / \mathrm{d}$ as the literature reported [60], in which the parameter $\mathrm{d}$ refers to the diameter of gold particles. Based on the above consideration, the TOF of $\mathrm{Au}_{25} / \mathrm{MgAl}-300$ and $\mathrm{Au}_{25} / \mathrm{Al}_{2} \mathrm{O}_{3}-300$ increased to $3078 \mathrm{~h}^{-1}$ and $2892 \mathrm{~h}^{-1}$, respectively. 
Table 2. Catalytic performances of supported Au catalysts in benzyl alcohol oxidation.

\begin{tabular}{|c|c|c|c|c|c|c|c|}
\hline $\begin{array}{r}\text { Benzyl } \\
\text { B }\end{array}$ & & $\begin{array}{r}\text { Benzal } \\
\text { B }\end{array}$ & & $\begin{array}{c}\text { Benzoic ac } \\
\text { BC }\end{array}$ & & $\begin{array}{c}\text { Benzyl benzc } \\
\text { BO }\end{array}$ & \\
\hline \multirow{2}{*}{ Entry } & \multirow{2}{*}{ Catalyst } & \multirow{2}{*}{$\underset{\mathrm{mmol} \%}{\mathrm{Au}}$} & \multirow{2}{*}{$\begin{array}{c}\text { Conversion } \\
(\%)^{a}\end{array}$} & \multicolumn{2}{|c|}{ Selectivity (\%) ${ }^{a}$} & \multirow{2}{*}{ TOF $\left(h^{-1}\right)^{b}$} & \multirow{2}{*}{ TOF $\left(h^{-1}\right)$} \\
\hline & & & & BZ & BO & & \\
\hline 1 & $\mathrm{Au}_{25} / \mathrm{MgAl}-300$ & 0.27 & 89.5 & 95.0 & 5.0 & 993 & 2979 \\
\hline 2 & $\mathrm{Au}_{25} / \mathrm{ZnAl}-300$ & 0.37 & 69.7 & 94.7 & 5.3 & 569 & 1536 \\
\hline 3 & $\mathrm{Au}_{25} / \mathrm{MgO}-300$ & 0.26 & 26.8 & 97.4 & 2.6 & 184 & 478 \\
\hline 4 & $\mathrm{Au}_{25} / \mathrm{ZnO}-300$ & 0.21 & 14.8 & 49.7 & 0.5 & 125 & 338 \\
\hline 5 & $\mathrm{Au}_{25} / \mathrm{Al}_{2} \mathrm{O}_{3}-300$ & 0.19 & 87.2 & 94.9 & 5.1 & 1033 & 2892 \\
\hline 6 & $\mathrm{Au}_{25} / \mathrm{SiO}_{2}-300$ & 0.20 & 14.2 & 0.6 & 0 & 143 & 844 \\
\hline 7 & $\mathrm{Au}_{25} / \mathrm{MgAl}-300(1 \%)^{\mathrm{d}}$ & 0.28 & 74.0 & 96.9 & 3.1 & 846 & 2792 \\
\hline 8 & $\mathrm{Au} / \mathrm{MgAl}-300-\mathrm{DP}$ e & 0.20 & 10.9 & 56.3 & 0.5 & 102 & 1051 \\
\hline 9 & $\mathrm{Au} / \mathrm{MgAl}-300-\mathrm{IMP}$ e & 0.25 & 7.4 & 38.6 & 0 & 61 & 628 \\
\hline 10 & $\mathrm{Au}_{25} / \mathrm{MgAl}-\mathrm{HT}$ & 0.25 & 8.1 & 4.3 & 0 & - & - \\
\hline 11 & MgAl-300 & - & 5.4 & 1.3 & 0 & - & - \\
\hline 12 & Blank & - & 0 & 0 & 0 & - & - \\
\hline
\end{tabular}

Reaction conditions: amounts of catalyst: $100 \mathrm{mg}$; substrate: $1 \mathrm{mmol}$; solvent: $10 \mathrm{~mL}$ of toluene; reaction temperature: $80{ }^{\circ} \mathrm{C} ; \mathrm{O}_{2}$ pressure: $1 \mathrm{~atm} ; \mathrm{O}_{2}$ flow rate: $30 \mathrm{~mL} / \mathrm{min}$; reaction time: $2 \mathrm{~h}$. ${ }^{a}$ Conversion and Selectivity were calculated with the results of gas chromatography; ${ }^{b}$ Turnover frequency (TOF) was calculated by moles of converted alcohol per mole of gold per hour, the reaction rate was calculated below $20 \%$ conversion; ${ }^{\mathrm{c}}$ TOF was measured by moles of converted alcohol per mole of gold with dispersion per hour, the dispersion of gold was roughly estimated according to the empirical equation of $1 / \mathrm{d}$ (d: diameter); ${ }^{\mathrm{d}}$ Catalyst: $50 \mathrm{mg}$; ${ }^{\mathrm{e}}$ Reaction time: $30 \mathrm{~min}$.

Inferior to the $\mathrm{Au}_{25} / \mathrm{MgAl}-300$ and $\mathrm{Au}_{25} / \mathrm{Al}_{2} \mathrm{O}_{3}-300$ catalysts was the $\mathrm{Au}_{25} / \mathrm{ZnAl}-300$, and the TOF value of it was $1536 \mathrm{~h}^{-1}$ for consideration of the dispersion of gold (Table 2, entry 2). Subsequently, the $\mathrm{Au}_{25} / \mathrm{SiO}_{2}-300, \mathrm{Au}_{25} / \mathrm{MgO}-300$, and $\mathrm{Au}_{25} / \mathrm{ZnO}-300$ catalysts ranked the following orders, with the TOF values of 844,478 , and $338 \mathrm{~h}^{-1}$, respectively. It was interesting to see that the $\mathrm{Au}_{25} / \mathrm{SiO}_{2}-300$, $\mathrm{Au}_{25} / \mathrm{MgO}-300$, and $\mathrm{Au}_{25} / \mathrm{ZnO}-300$ catalysts showed very poor activity in this reaction (Table 2, entry 3, 4, 6), with the TOF values far below that of the $\mathrm{Au}_{25} / \mathrm{MgAl}-300$ and $\mathrm{Au}_{25} / \mathrm{Al}_{2} \mathrm{O}_{3}-300$ catalysts. Furthermore, the yields of products did not equilibrate with the transformed reactant over the $\mathrm{Au}_{25} / \mathrm{SiO}_{2}-300$ and $\mathrm{Au}_{25} / \mathrm{ZnO}-300$ catalysts, which might be caused by the absorption of intermediates on both catalysts. The above results indicated that the support effect might play an essential role in aerobic oxidation of benzyl alcohol.

To clarify the size effect, the gold catalysts with different loadings of gold or different methods were also prepared in this reaction for comparison. The results were listed in Table 2, entry 7-9. It indicated the catalytic performances were not largely affected by the loadings of gold, in which the TOF values were $2792 \mathrm{~h}^{-1}$ for $1.1 \% \mathrm{Au}_{25} / \mathrm{MgAl}-300$ catalyst and $3000 \mathrm{~h}^{-1}$ for $0.5 \% \mathrm{Au}_{25} / \mathrm{MgAl}-300$ catalyst (Table 2, entries 1 and 7), with the mean particle sizes of $3.0 \mathrm{~nm}$ (Figure 4) and $3.3 \mathrm{~nm}$ (Figure S5), respectively. However, the activities of $\mathrm{Au} / \mathrm{MgAl}-300-\mathrm{DP}$ and $\mathrm{Au} / \mathrm{MgAl}-300-\mathrm{IMP}$ catalysts prepared by traditional deposition precipitation (DP) method and incipient-wetness impregnation (IMP) method were far below that of the $\mathrm{Au}_{25} / \mathrm{MgAl}-300$ catalyst, with TOF values of 1051 and $628 \mathrm{~h}^{-1}$, respectively (Table 2, entries 8 and 9). In addition, when the dispersion of gold was not taken into account, their gaps of TOF values with the supported $\mathrm{Au}_{25} \mathrm{NCs}$ catalyst were even larger. This phenomenon suggested that the size effect could influence the catalytic performances at the specific conditions.

\subsection{The Influence Factors for Aerobic Oxidation of Benzyl Alcohol over the Supported Gold Catalysts}

Based on the above characterizations and catalytic performances in this work, the influence factors for aerobic oxidation of benzyl alcohol over the supported gold catalysts were then discussed. According to an $\mathrm{N}_{2}$-physical adsorption-desorption test, the specific area and the pore volume of 
$\mathrm{Au}_{25} / \mathrm{MgO}-300$ and $\mathrm{Au}_{25} / \mathrm{ZnO}-300$ catalysts were obviously smaller than the others (Figure 1 and Table 1), which might lead to their poor activities in oxidation of benzyl alcohol, since the low specific area and small pore volume might hamper the adsorption of substrates onto the catalysts [43].

However, the $\mathrm{Au}_{25} / \mathrm{SiO}_{2}-300$ catalyst which holds a comparably high specific area also exhibited poor activity, which implied that the catalytic performances were not solely influenced by the pore structure. Actually, it is well known that the particle sizes of gold played a vital role in gold catalysts for a large amount of reactions $[3,24,37,61]$. Because the small gold particles had a higher fraction of low-coordinated atoms, which was proposed to account for the specific catalytic activities [24]. In this study, as demonstrated by TEM results, the mean particle size of gold in $\mathrm{Au}_{25} / \mathrm{SiO}_{2}-300$, $\mathrm{Au} / \mathrm{MgAl}-300-\mathrm{DP}$ and $\mathrm{Au} / \mathrm{MgAl}-300-\mathrm{MP}$ catalysts were greater than that of the other supported gold catalysts (Figure $4 \mathrm{f}$ and Figure S6). Thus, the different catalytic performances could be affected by the particle sizes. Nevertheless, for $\mathrm{Au}_{25} / \mathrm{MgO}-300$ and $\mathrm{Au}_{25} / \mathrm{ZnO}-300$ catalysts, the mean particle sizes of gold were almost the same as that in $\mathrm{Au}_{25} / \mathrm{MgAl}-300, \mathrm{Au}_{25} / \mathrm{ZnAl}-300$ and $\mathrm{Au}_{25} / \mathrm{Al}_{2} \mathrm{O}_{3}-300$ catalysts, which bear a particle size within $3 \mathrm{~nm}$, while their performances were totally different. This suggests that the catalytic performances were not influenced by the size effect alone.

We summarized the trend about size effect in Figure 8. The star-like icons with different colors displayed the various supported gold catalysts. The horizontal coordinates represented the diameter of gold, and the vertical coordinates revealed the TOF values based on the surface gold. From the data, the catalytic performances of gold catalysts with sizes below $5 \mathrm{~nm}$ seem to be independent from the particle size, while the dimensions above $5 \mathrm{~nm}$ displayed the obvious size-dependent property. Thus, in a small scale, the activities might be influenced by the other factor instead of the size.

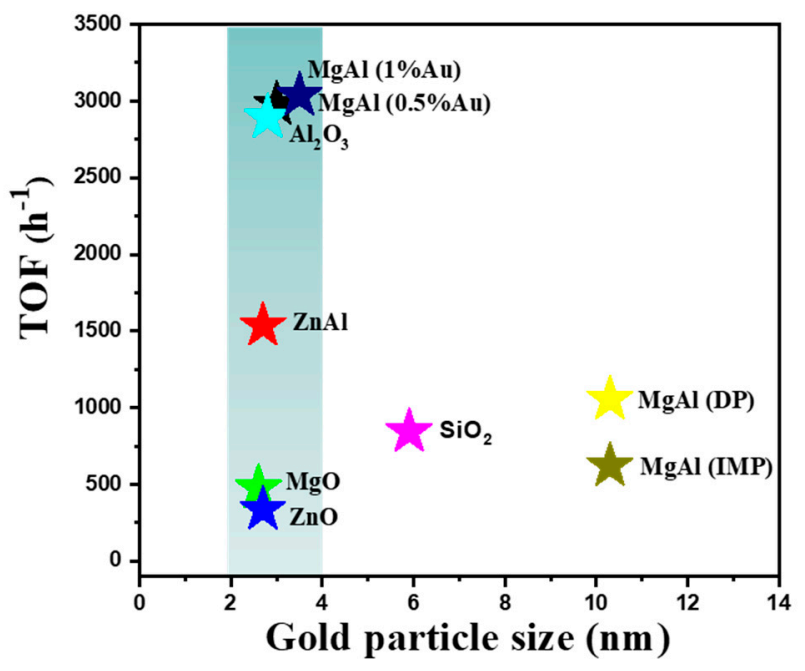

Figure 8. The relationship between turnover frequency values with the particle sizes on different supported gold catalysts with various supports and preparation methods.

The interaction between gold and the support was often reported to make a big difference in catalytic reactions by modifying the electronic properties of gold [33,34]. In this study, we found the interaction between gold and the $\mathrm{SiO}_{2}$ was too weak to influence the nature of gold. However, it really worked in some other supports, since the valent state of gold was negatively shifted (Figure 5). Although the interaction between gold and the supports were strong in $\mathrm{Au}_{25} / \mathrm{MgO}-300$ and $\mathrm{Au}_{25} / \mathrm{ZnO}-300$ catalysts, their performances were not as good as $\mathrm{Au}_{25} / \mathrm{MgAl}-300$, and even inferior to $\mathrm{Au}_{25} / \mathrm{SiO}_{2}-300$. Thus, it can be concluded that the interaction between gold and the support might not be the key influence factor for catalytic performances of benzyl alcohol oxidation in this system.

The aerobic oxidation of alcohols was usually performed in the presence of a base, which was viewed as essential to form an alkoxide intermediate by the activation of the $\mathrm{O}-\mathrm{H}$ bond of the alcohol $[20,45,59]$. The base additive such as $\mathrm{KOH}$ and $\mathrm{K}_{2} \mathrm{CO}_{3}$ were often deemed as an efficient 
promoter especially when the support has no basicity $[16,20]$. However, these additives had big problems of contamination and separation that would greatly prevent its further application in industry. Thus, in this work, the experiments were conducted in the absence of any inorganic base. Thus, the basicity originated from the support was probably important for the performance. Moreover, it was said that the acid sites on the support could facilitate for the metal hydride with oxygen to produce water $[25,45]$. Hence, the promotion of acidity was also needed to give a reasonable explanation.

Linking the reaction performance with the acid-base properties, it was interesting to find that the order of catalytic performances agreed well with the sequence of acid-base quantities. This meant that the catalysts with more amounts of basic and acidic sites showed better activities than the ones with fewer acid-base sites. It implies that the content of base and acid plays a vital role in aerobic oxidation of benzyl alcohol. In addition, the catalytic activity might be affected simultaneously by both the acidic and basic sites.

The total adsorption amounts of $\mathrm{CO}_{2}, \mathrm{NH}_{3}$ as well as $\mathrm{O}_{2}$ over different supported gold catalysts were illustrated in Figure 9a. Notably, the adsorption of $\mathrm{O}_{2}$ was not much different in various supported gold catalysts. This implied that the adsorption and dissociation of $\mathrm{O}_{2}$ might not be the rate-determining step of this reaction. In addition, the relationship between TOF values with the total basicity and acidity was observed in Figure 9 b. It clearly suggests that the catalysts with both basic and acid sites displayed good performances in aerobic oxidation of benzyl alcohol, whereas the strength of basicity and acidity displayed no obvious effect in catalytic performances. To be noted, based on the results in Table 2, the catalysts with more basic sites afford higher selectivity towards benzaldehyde, while the catalysts with more acid sites were more active for the conversion of benzyl alcohol.
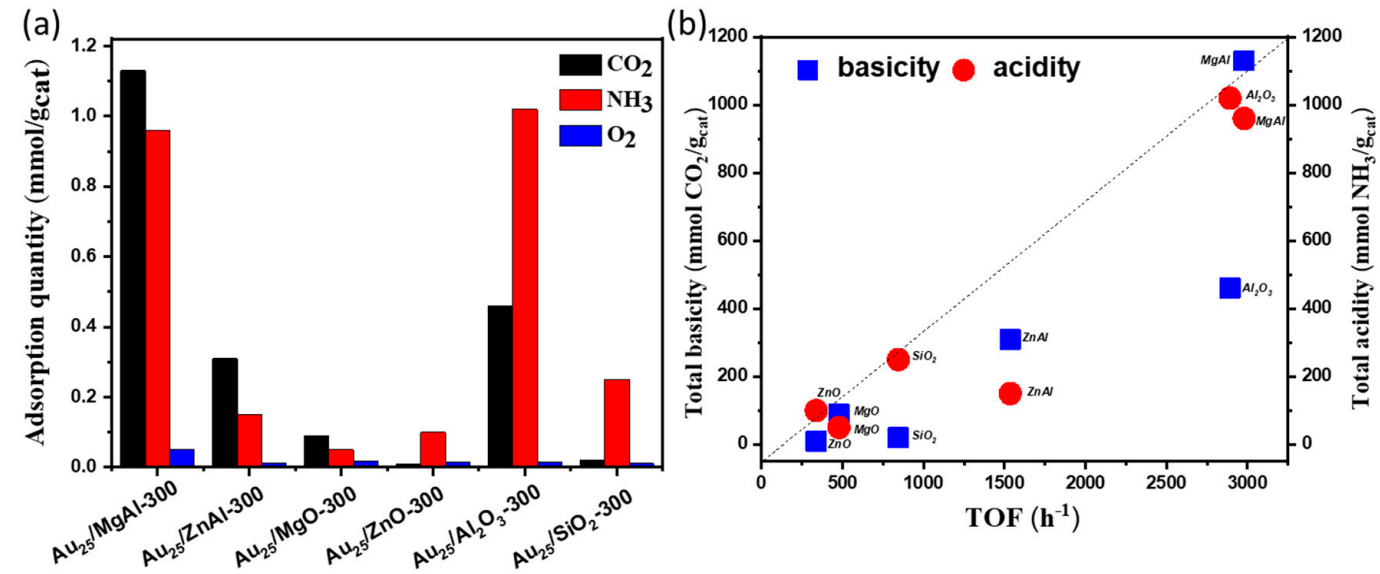

Figure 9. (a) the comparison of adsorption quantities of $\mathrm{CO}_{2}, \mathrm{NH}_{3}$ and $\mathrm{O}_{2}$ over the different supported gold catalysts by pulse adsorption tests; (b) the relationship between TOF values with the total basicity and acidity over different supported gold catalysts.

\subsection{The Proposed Reaction Mechanism}

Based on the previous literature $[20,25,45,59]$ and the above results in this work, we proposed an acid-base promoted mechanism for aerobic oxidation of benzyl alcohol (Figure 10). At this situation, the catalysts should exhibit both basicity and acidity. Among them, the base acts as the sites to cleave the O-H bond of the alcohol, in order to form an alkoxide intermediate [20,25,45], while the acid site might participate in the reaction of transforming the metal hydride and the oxygen to form water $[45,46]$. To be noted, the blank experiment and the support itself were not active for this reaction (Table 2, entries 11 and 12), which suggests that the gold and the supports synergistically catalyzed the reaction. Furthermore, the uncalcined $\mathrm{Au}_{25} / \mathrm{MgAl}-\mathrm{HT}$ sample showed extreme low activity and selectivity (Table 2, entry 10), which indicates that the exposed gold atoms after removal of the protectant were critical for the reaction, and the active sites might be located at the interface of gold with the support [62]. 


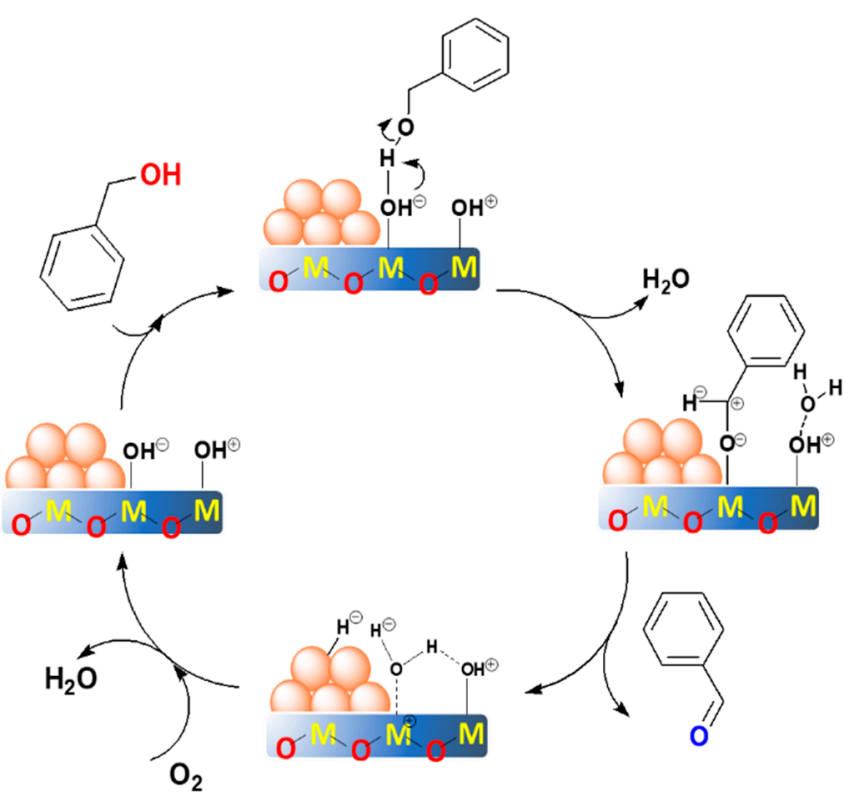

Figure 10. The proposed reaction mechanism over the supported gold catalysts with the synergetic acid-base sites. The $\mathrm{M}$ refers to the metal cation.

The proposed reaction mechanism could be divided into four steps. In the first step, the benzyl alcohol attacked the basic site of $\mathrm{M}-\mathrm{OH}^{\delta-}$ on the supports. Then, the deprotonation by the hydroxyl group of the support occurred to form an alkoxide intermediate at the interface. Simultaneously, the molecule water was formed in the process. After that, the alkoxide intermediate proceeded with the coordination with the gold to form a metal-hydride species. Synchronously, the $\beta$-hydride was eliminated from the interface by the gold to produce the benzaldehyde. According to literature [25,45], this step might play a significant role in determining the selectivity of benzaldehyde. In addition, the process was expected to be the rate-determining step. This was why the small gold particles exhibited higher activity - because the coordinatively unsaturated gold atoms with smaller sizes were more active for the cleavage of the $\mathrm{C}-\mathrm{H}$ bond. However, when the particle sizes were within a small range, the acid-base property dominated the reaction rate instead of the particle size. In the last step, the reaction underwent a rapid oxidation of the metal-hydride specie by oxygen to form the water, which promoted by the acid site of the support. Then, the catalysts recovered at the initial metallic state, thereby to complete the catalytic cycle. For the $\mathrm{Au}_{25} / \mathrm{MgAl}-300$ catalyst, we also examined the recyclability for the oxidant of benzyl alcohol. As shown in Figure S7, the conversion of benzyl alcohol decreased from $87 \%$ to $19 \%$ after reusing five times. This means that the $\mathrm{Au}_{25} / \mathrm{MgAl}-300$ catalyst was not very stable in the reaction. The TEM results of $\mathrm{Au}_{25} / \mathrm{MgAl}-300$ catalyst after reusing three times indicated that the particle sizes of gold increased from $3.0 \mathrm{~nm}$ (Figure 4a) to $4.5 \mathrm{~nm}$ (Figure S8), and agglomeration appeared in part of the catalyst, which might be deemed as a key point for the reduction of catalytic performance.

In summary, we proposed a reaction mechanism of acid-base synergistically catalyzed the reaction route with the help of small gold particles based on the experiment results and characterizations. The fundamental reasons for the high activity and selectivity were provided to give a deep understanding of the system. This was crucial to make it clear how the different factors influenced the catalytic performances. 


\section{Materials and Methods}

\subsection{Materials}

The main chemicals were purchased from Aladdin (Georgia, USA). The $\mathrm{MgO}$ and $\mathrm{ZnO}$ were pretreated at $500^{\circ} \mathrm{C}$ for $4 \mathrm{~h}$ before use to remove the impurity. The $\mathrm{Al}_{2} \mathrm{O}_{3}$ was obtained by calcination of $\mathrm{Al}(\mathrm{OH})_{3}$ at $500{ }^{\circ} \mathrm{C}$ for $3 \mathrm{~h}$. The $\mathrm{SiO}_{2}$ was functionalized with 3-aminopropyltriethoxysilane (APTES, $99 \%$ ) by heating at $80^{\circ} \mathrm{C}$ in alcohol under reflux for $24 \mathrm{~h}$. The MgAl-HT and ZnAl-HT were homemade by solution synthesis. The other chemicals in the experiment were used without further purification.

\subsection{Preparation of the $\mathrm{Au}_{25} \mathrm{NCs}$}

The hydrosoluble $\mathrm{Au}_{25} \mathrm{NC}$ s were synthesized according to the literature [37]. In a typical synthesis, $0.5 \mathrm{mmol}$ of the $\mathrm{HAuCl}_{4}$ solution and $0.75 \mathrm{mmol}$ of the cysteine solution were added successively to $150 \mathrm{~mL}$ of deionized water under vigorous stirring. After that, $30 \mathrm{~mL}$ of $\mathrm{NaOH}$ solution $(1 \mathrm{M})$ was introduced into the mixture. Then, five times of the equivalent $\mathrm{NaBH}_{4}$ solution were freshly prepared and added to the above solution, followed by vigorous stirring for $3 \mathrm{~h}$. Finally, the products were washed repeatedly with the ethanol/water mixture $(V / V=3: 1)$ and collected after lyophilization to obtain the $\mathrm{Au}_{25}$ nanoclusters.

\subsection{Preparation of the Hydrotalcite (HT)}

The ZnAl-HT and MgAl-HT supports were prepared as follows. Firstly, solution A was obtained by adding $0.21 \mathrm{~mol}$ of $\mathrm{Zn}\left(\mathrm{NO}_{3}\right)_{2} \cdot 6 \mathrm{H}_{2} \mathrm{O}$ or $\mathrm{Mg}\left(\mathrm{NO}_{3}\right)_{2} \cdot 6 \mathrm{H}_{2} \mathrm{O}$ and $0.07 \mathrm{~mol}$ of $\mathrm{Al}\left(\mathrm{NO}_{3}\right)_{3} \cdot 9 \mathrm{H}_{2} \mathrm{O}$ into $200 \mathrm{~g}$ of deionized water. Secondly, solution $\mathrm{B}$ was prepared by adding $0.438 \mathrm{~mol}$ of $\mathrm{NaOH}$ and $0.113 \mathrm{~mol}$ of $\mathrm{Na}_{2} \mathrm{CO}_{3}$ into $200 \mathrm{~g}$ of deionized water. Then, solution A was slowly added to solution $\mathrm{B}$ under constant stirring at $75^{\circ} \mathrm{C}$ for $24 \mathrm{~h}$. Finally, the mixture was filtered and washed with distilled water for several times. The obtained precipitate was further dried at $80^{\circ} \mathrm{C}$.

\subsection{Preparation of the Supported $A u_{25}$ Nanoclusters (NCs)}

The supported Au NCs were synthesized via the impregnation method. Typically, $15 \mathrm{mg}$ of the cysteine-caped $\mathrm{Au}_{25} \mathrm{NCs}$ were dissolved in $20 \mathrm{~mL}$ of deionized water. Then, $2.00 \mathrm{~g}$ of the supports were added to the above suspension under gentle stirring. After $1 \mathrm{~h}$, the products were washed with water and collected by centrifugation. The residue was then dried at $80^{\circ} \mathrm{C}$ and calcined at $300{ }^{\circ} \mathrm{C}$ for $2 \mathrm{~h}$ to obtain the samples. The obtained samples were denoted as $\mathrm{Au}_{25} / \mathrm{MgAl}-300, \mathrm{Au}_{25} / \mathrm{ZnAl}-300$, $\mathrm{Au}_{25} / \mathrm{ZnO}-300, \mathrm{Au}_{25} / \mathrm{MgO}-300, \mathrm{Au}_{25} / \mathrm{Al}_{2} \mathrm{O}_{3}-300$, and $\mathrm{Au}_{25} / \mathrm{SiO}_{2}-300$. For comparison, the supported gold NCs with different loadings of Au were prepared by regulating the amounts of $\mathrm{Au}_{25}$.

\subsection{Preparation of the Supported Au Nanoparticles (NPs)}

In comparison to the supported $\mathrm{Au}_{25} \mathrm{NCs}$ catalysts, the gold nanoparticles were synthesized by the traditional deposition precipitation (DP) method and incipient-wetness impregnation (IMP) method. In a typical DP method, the $\mathrm{pH}$ of the $\mathrm{HAuCl}_{4}$ solution was firstly adjusted to nearly 7 with $0.1 \mathrm{M} \mathrm{NaOH}$ solution. Then, the support was added to the solution under vigorous stirring. After the $\mathrm{pH}$ reached to about 9 with $\mathrm{NaOH}$ solution, the solution was filtered, washed with $500 \mathrm{~mL}$ of ultrapure water, and dried overnight in an oven at $80^{\circ} \mathrm{C}$. In the IMP method, a special volume of the $\mathrm{HAuCl}_{4}$ solution was prepared in advance. Then, the solution was slowly added to $2 \mathrm{~g}$ of the support under continuous stirring until the dry powder was saturated with the solution. After that, the wet powder dried $80^{\circ} \mathrm{C}$. In addition, before evaluating for the reaction test, they were calcined at $300^{\circ} \mathrm{C}$ for $2 \mathrm{~h}$.

\subsection{Characterization of the Catalysts}

The actual content of gold in the catalysts was measured with an inductively coupled plasma atomic emission spectrometer (ICP-AES) on an IRIS Intrepid II XSP instrument (Thermo Electron 
Corporation, Madison, USA). The measured amounts of catalysts were dissolved in a fresh aqua regia and hydrofluoric acid at boiling condition and diluted to $50 \mathrm{~mL}$ for analysis. Power X-ray diffraction (XRD) were determined on a PW3040/60 X'Pert PRO (PANalytical, Almelo, Netherlands) diffract meter equipped with a $\mathrm{Cu} K \alpha$ radiation source $(\lambda=0.15432 \mathrm{~nm})$ operating at $40 \mathrm{kV}$ and $40 \mathrm{~mA}$. The continuous mode was used at a scanning speed of $10^{\circ} / \mathrm{min}$ in the scanning angle $(2 \theta)$ range from $10^{\circ}$ to $90^{\circ}$. UV-vis spectra were recorded on a Cintra (Austin, USA) (GBC) apparatus with $\mathrm{BaSO}_{4}$ as the reference at room temperature. A continuous mode at a scanning speed of $100 \mathrm{~nm} / \mathrm{min}$ was used from 200 to $800 \mathrm{~nm}$. The texture properties of the catalysts were measured by $\mathrm{N}_{2}$-physical adsorption-desorption test at $77 \mathrm{~K}$ using an AutoSorb-1 instrument (Florida, USA). Prior to the measurements, the catalysts were treated at vacuum for $2 \mathrm{~h}$ at $120^{\circ} \mathrm{C}$. The pore volume and pore size distribution were determined from the adsorption branches using the NLDFT (the nonlocal density functional theory) method. The transmission electron microscopy (TEM) was recorded with a JEM-2100F field emission (Tokyo, Japan) TEM. The microstructure of the catalysts was further observed by high resolution transmission electron microscopy (HRTEM) at $200 \mathrm{kV}$. The temperature-programmed desorption of carbon dioxide $\left(\mathrm{CO}_{2}\right.$-TPD), ammonia $\left(\mathrm{NH}_{3}-\mathrm{TPD}\right)$, and oxygen $\left(\mathrm{O}_{2}\right.$-TPD) experiments were performed on AutochemII 2920 Instruments (Norcross, Georgia, USA) with a thermal conductivity detector. Prior to the analysis, about $50 \mathrm{mg}$ of the catalysts were added into a U-type quartz tube reactor, and then the sample was heated in a flow of helium at $300{ }^{\circ} \mathrm{C}$ for $1 \mathrm{~h}$. After the temperature decreased to $80{ }^{\circ} \mathrm{C}$, the catalysts were saturated with $\mathrm{CO}_{2}, \mathrm{NH}_{3}$ and $\mathrm{O}_{2}$ at $80^{\circ} \mathrm{C}$ for 20 times. Then, the sample was purged in helium at $50{ }^{\circ} \mathrm{C}$ for $1 \mathrm{~h}$. Finally, the $\mathrm{CO}_{2} / \mathrm{NH}_{3} / \mathrm{O}_{2}$-TPD signal was recorded from $100{ }^{\circ} \mathrm{C}$ to $800{ }^{\circ} \mathrm{C}$ at a rate of $10^{\circ} \mathrm{C} / \mathrm{min}$ with a cold trap. X-ray photoelectron spectra (XPS) were conducted on an ESCALAB 250 $\mathrm{X}$-ray photoelectron spectrometer (Madison, USA) equipped with a monochromated Al K $\alpha$ anode. The binding energies of $\mathrm{Au} 4 \mathrm{f}$ were calibrated for surface charging by referencing them to the energy of the $\mathrm{C} 1 \mathrm{~s}$ peak at $284.6 \mathrm{eV}$.

\subsection{Aerobic Oxidation of Alcohols}

The aerobic oxidation of benzyl alcohol was performed in a three-necked flask. In a typical reaction, $100 \mathrm{mg}$ of the catalysts were added in the reactor. Then, $1 \mathrm{mmol}$ substrate dissolved in $10 \mathrm{~mL}$ toluene was added without addition of any inorganic bases. The o-xylene was used as the internal reference. The reaction was conducted at $80^{\circ} \mathrm{C}$ under stirring. After the temperature reached a fixed value, the $\mathrm{O}_{2}$ was bubbled through the solution at atmospheric pressure with the gas flow of $30 \mathrm{~mL} / \mathrm{min}$. The products were analyzed by gas chromatography (Agilent 7890 GC, California, USA) equipped with a HP-5 capillary column $(25 \mathrm{~m} \times 0.32 \mathrm{~mm})$ and flame ionization detector (FID). The initial reaction rate and the turnover frequency (TOF) were measured below $20 \%$ conversion.

\section{Conclusions}

In this work, the $\mathrm{MgAl}-\mathrm{HT}, \mathrm{ZnAl}-\mathrm{HT}, \mathrm{ZnO}, \mathrm{MgO}, \mathrm{Al}_{2} \mathrm{O}_{3}$, and $\mathrm{SiO}_{2}$ supported $\mathrm{Au}_{25} \mathrm{NC}$ s catalysts were successfully synthesized. Characterization results of XRD, UV-vis, and TEM implied that the gold particles were uniformly distributed on the supports, with a mean particle size within $3 \mathrm{~nm}$ in most of the above catalysts. For aerobic oxidation of benzyl alcohol, the $\mathrm{Au}_{25} / \mathrm{MgAl}-300$ and $\mathrm{Au}_{25} / \mathrm{Al}_{2} \mathrm{O}_{3}-300$ catalysts presented the best activities, with the TOF values of $\sim 2927$ and $2892 \mathrm{~h}^{-1}$, respectively. The next one was the $\mathrm{Au}_{25} / \mathrm{ZnAl}-300$, with a TOF of $1536 \mathrm{~h}^{-1}$. The $\mathrm{Au}_{25} / \mathrm{ZnO}-300$, $\mathrm{Au}_{25} / \mathrm{MgO}-300$, and $\mathrm{Au}_{25} / \mathrm{SiO}_{2}-300$ catalysts displayed poor activities. Based on the TEM, HRTEM, and XPS measurements, the morphology and size distributions of gold as well as the interaction between gold with the supports were largely affected by the supports effect. These factors might not be the key points for catalytic performances, but the acid-base property might be the critical one. The synergic catalytic route between the acid site and the basic site was proposed over the supported $\mathrm{Au}_{25} \mathrm{NCs}$ catalysts. We believe that this work provided a good way to design the gold catalysts with controllable sizes, and it was crucial for understanding the reaction process in aerobic oxidation of alcohol. 
Supplementary Materials: The following are available online at http://www.mdpi.com/2073-4344/10/1/107/s1, Figure S1: $\mathrm{N}_{2}$ adsorption/desorption isotherms and pore size distributions of different supports, Figure S2: XRD patterns of different supports, Figure S3: HRTEM images of different supported gold catalysts, Figure S4: XPS spectra of $\mathrm{O} 1 \mathrm{~s}$ on different supported gold catalysts, Figure S5: TEM image and size distribution histogram of $1.1 \% \mathrm{Au}_{25} / \mathrm{MgAl}-300$ catalyst, Figure S6: TEM images and size distribution histograms of gold catalysts with different preparation methods, Figure S7: The reusability of $\mathrm{Au}_{25} / \mathrm{MgAl}-300$ catalyst in benzyl alcohol oxidation, Figure S8: The TEM images and size distributions of $\mathrm{Au}_{25} / \mathrm{MgAl}-300$ catalyst after reusing three times, Table S1: Physicochemical properties of different supports, Table S2: The adsorption quantities of $\mathrm{CO}_{2}, \mathrm{NH}_{3}$ and $\mathrm{O}_{2}$ over different supported gold catalysts.

Author Contributions: Y.T. and Y.D. conceived the study; L.L. and H.L. performed the experiments; X.C., S.W., and X.W. contributed with the materials; W.Y., C.H., and M.Z. contributed with characterizations; R.L. and X.Y.L. contributed with the useful advice; and all of the authors contributed to the writing of the manuscript. All authors have read and agreed to the published version of the manuscript.

Funding: This research was supported by the National Natural Science Foundation of China under Grant Nos. 21776271, 21803056, and 21973084; and Zhejiang Provincial Natural Science Foundation of China under Grant Nos. LQ18B030003, LQ20B030005 and LQ20B030008.

Acknowledgments: The authors would like to thank the public testing platform of Zhejiang Normal University and Dalian Institute of Chemical Physics, Chinese Academy of Sciences. The authors are also thankful for the equipment support with ICP, XRD, UV-vis, TEM, HRTEM, and XPS measurements.

Conflicts of Interest: The authors declare no conflict of interest.

\section{References}

1. Hutchings, G.J. Vapor Phase Hydrochlorination of Acetylene: Correlation of Catalytic Acitivity of Supported Metal Chloride Catalysts. J. Catal. 1985, 96, 292-295. [CrossRef]

2. Harauta, M.; Kobayashi, T.; Sano, H.; Yamada, N. Novel Gold Catalyst for the Oxidation of Carbon Monoxide at a Temperature far Below $0{ }^{\circ} \mathrm{C}$. Chem. Lett. 1987, 16, 405-408. [CrossRef]

3. Harauta, M. Size-and Support-Dependency in the Catalysis of Gold. Catal. Today 1997, 36, 153-166. [CrossRef]

4. Min, B.K.; Friend, C.M. Heterogeneous Gold-Based Catalysis for Green Chemistry: Low-Temperature CO Oxidation and Propene Oxidation. Chem. Rev. 2007, 107, 2709-2724. [CrossRef] [PubMed]

5. Li, W.C.; Comotti, M.; Schüth, F. Highly Reproducible Syntheses of Active $\mathrm{Au} / \mathrm{TiO}_{2}$ Catalysts for CO Oxidation by Deposition-Precipitation or Impregnation. J. Catal. 2006, 237, 190-196. [CrossRef]

6. Zhao, K.; Tang, H.; Qiao, B.; Li, L.; Wang, J. High Activity of $\mathrm{Au} / \gamma-\mathrm{Fe}_{2} \mathrm{O}_{3}$ for CO Oxidation: Effect of Support Crystal Phase in Catalyst Design. ACS Catal. 2015, 5, 3528-3539. [CrossRef]

7. Corma, A.; Serna, P. Chemoselective Hydrogenation of Nitro Compounds with Supported Gold Catalysts. Science 2006, 313, 332-335. [CrossRef] [PubMed]

8. Hashmi, A.S.K.; Hutchings, G.J. Gold catalysis. Angew. Chem. Int. Ed. 2006, 45, 7896-7936. [CrossRef]

9. Chen, H.; Cullen, D.A.; Larese, J.Z. Highly Efficient Selective Hydrogenation of Cinnamaldehyde to Cinnamyl Alcohol over Gold Supported on Zinc Oxide Materials. J. Phys. Chem. C 2015, 119, 28885-28894. [CrossRef]

10. Zhang, Y.; Cui, X.; Shi, F.; Deng, Y. Nano-Gold Catalysis in Fine Chemical Synthesis. Chem. Rev. 2012, 112, 2467-2505. [CrossRef]

11. Li, G.; Jin, R. Catalysis by Gold Nanoparticles: Carbon-Carbon Coupling Reactions. Nanotechnol. Rev. 2013, 2, 529-545.

12. Zhou, Y.; Li, G.A. Critical Review on Carbon-Carbon Coupling over Ultra-Small Gold Nanoclusters. Acta Phys. Chim. Sin. 2017, 33, 1297-1309.

13. Shi, Q.; Qin, Z.; Xu, H.; Li, G. Heterogeneous Cross-Coupling over Gold Nanoclusters. Nanomaterials 2019, 9 , 838-854. [CrossRef] [PubMed]

14. Abad, A.; Almela, C.; Corma, A.; Garía, H. Unique Gold Chemoselectivity for the Aerobic Oxidation of Allylic Alcohols. Chem. Commun. 2006, 30, 3178-3180. [CrossRef]

15. Li, L.; Dou, L.; Zhang, H. Layered Double Hydroxide Supported Gold Nanoclusters by Glutathione-Capped Au Nanoclusters Precursor Method for Highly Efficient Aerobic Oxidation of Alcohols. Nanoscale 2014, 6, 3753-3763. [CrossRef]

16. Pina, C.D.; Falletta, E.; Rossi, M. Update on Selective Oxidation Using Gold. Chem. Soc. Rev. 2012, 41, 350-369. [CrossRef] 
17. Su, F.Z.; Liu, Y.M.; Wang, L.C.; Cao, Y.; He, H.; Fan, K.N. Ga-Al Mixed-Oxide-Supported Gold Nanoparticles with Enhanced Activity for Aerobic Alcohol Oxidation. Angew. Chem. Int. Ed. 2008, 120, 340-343. [CrossRef]

18. Asao, N.; Hatakeyama, N.; Menggenbateer; Minato, T.; Ito, E.; Masahiko, H.; Kim, Y.; Yamamoto, Y.; Chen, M.; Zhang, W.; et al. Aerobic Oxidation of Alcohols in the Liquid Phase with Nanoporous Gold Catalysts. Chem. Commun. 2012, 48, 4540-4542. [CrossRef]

19. Gualteros, J.A.D.; Garcia, M.A.S.; da Silva, A.G.M.; Rodrigues, T.S.; Căndido, E.G.; e Silva, F.A.; Fonseca, F.C.; Quiroz, J.; de Oliveira, D.C.; Cordoba de Torresi, S.I.; et al. Synthesis of Highly Dispersed Gold Nanoparticles on $\mathrm{Al}_{2} \mathrm{O}_{3}, \mathrm{SiO}_{2}$, and $\mathrm{TiO}_{2}$ for the Solvent-Free Oxidation of Benzyl Alcohol under Low Metal Loadings. J. Mater. Sci. 2018, 54, 238-251. [CrossRef]

20. Nagy, G.; Beck, A.; Sáfrán, G.; Schay, Z.; Liu, S.; Li, T.; Qiao, B.; Wang, J.; Lázár, K. Nanodisperse Gold Catalysts in Oxidation of Benzyl Alcohol: Comparison of Various Supports under Different Conditions. React. Kinet. Mech. Catal. 2019, 128, 71-95. [CrossRef]

21. Long, N.Q.; Quan, N.A. Highly Selective Oxidation of Benzyl Alcohol to Benzaldehyde Catalyzed by $\mathrm{Nano} \mathrm{Au} / \gamma-\mathrm{Al}_{2} \mathrm{O}_{3}$ under Environment-Friendly Conditions. React. Kinet. Mech. Catal. 2014, 114, 147-155. [CrossRef]

22. Zhan, B.Z.; Thompson, A. Recent Developments in the Aerobic Oxidation of Alcohols. Tetrahedron 2004, 60, 2917-2935. [CrossRef]

23. Zhu, Y.; Qian, H.; Das, A.; Jin, R. Comparison of the Catalytic Properties of 25-Atom Gold Nanospheres and Nanorods. Chin. J. Catal. 2011, 32, 1149-1155. [CrossRef]

24. Taketoshi, A.; Haruta, M. Size- and Structure-Specificity in Catalysis by Gold Clusters. Chem. Lett. 2014, 43, 380-387. [CrossRef]

25. Fang, W.; Chen, J.; Zhang, Q.; Deng, W.; Wang, Y. Hydrotalcite-Supported Gold Catalyst for the Oxidant-Free Dehydrogenation of Benzyl Alcohol: Studies on Support and Gold Size Effects. Chemistry 2011, 17, 1247-1256. [CrossRef]

26. Comotti, M.; Li, W.C.; Spliethoff, B.; Schüth, F. Support Effect in High Activity Gold Catalysts for CO Oxidation. J. Am. Chem. Soc. 2006, 128, 917-924. [CrossRef]

27. Liu, X.Y.; Wang, A.; Zhang, T.; Mou, C.Y. Catalysis by Gold: New insights into the Support Effect. Nano Today 2013, 8, 403-416. [CrossRef]

28. Cárdenas Lizana, F.; Gómez Quero, S.; Perret, N.; Keane, M.A. Support Effects in the Selective Gas Phase Hydrogenation of $p$-chlronitrobenzene over Gold. Gold Bull. 2009, 42, 124-132.

29. Hodes, G. When Small is Different: Some Recent Advances in Concepts and Applications of Nanoscale Phenomena. Adv. Mater. 2007, 19, 639-655. [CrossRef]

30. Yang, X.F.; Wang, A.; Qiao, B.; Li, J.; Liu, J.; Zhang, T. Single-Atom Catalysts: A New Frontier in Heterogeneous Catalysis. Acc. Chem. Res. 2013, 46, 1740-1748. [CrossRef]

31. Nie, X.; Qian, H.; Ge, Q.; Xu, H.; Jin, R. CO Oxidation Catalyzed by Oxide-Supported $\mathrm{Au}_{25}(\mathrm{SR})_{18}$ Nanoclusters and Identification of Perimeter Sites as Active Centers. ACS Nano 2012, 6, 6014-6022. [CrossRef]

32. Wu, Z.; Jiang, D.; Mann, A.K.P.; Mullins, D.R.; Qiao, Z.A.; Allard, L.F.; Zeng, C.; Jin, R.; Overbury, S.H. Thiolate Ligands as a Double-Edged Sword for CO Oxidation on $\mathrm{CeO}_{2}$ Supported $\mathrm{Au}_{25}\left(\mathrm{SCH}_{2} \mathrm{CH}_{2} \mathrm{Ph}\right)_{18}$ Nanoclusters. J. Am. Chem. Soc. 2014, 136, 6111-6122. [CrossRef]

33. Liu, Y.; Tsunoyama, H.; Akita, T.; Tsukuda, T. Efficient and Selective Epoxidation of Styrene with TBHP Catalyzed by $\mathrm{Au}_{25}$ Clusters on Hydroxyapatite. Chem. Commun. 2010, 46, 550-552. [CrossRef] [PubMed]

34. Fang, J.; Li, J.; Zhang, B.; Yuan, X.; Asakura, H.; Tanaka, T.; Teramura, K.; Xie, J.; Yan, N. The Support Effect on the Size and Catalytic Activity of Thiolated $\mathrm{Au}_{25}$ Nanoclusters as Precatalysts. Nanoscale 2015, 7, 6325-6333. [CrossRef] [PubMed]

35. Li, G.; Liu, C.; Lei, Y.; Jin, R. Au 25 Nanocluster-catalyzed Ullmann-Type Homocoupling Reaction of Aryl Iodides. Chem. Commun. 2012, 48, 12005-12007. [CrossRef] [PubMed]

36. Shivhare, A.; Ambrose, S.J.; Zhang, H.; Purves, R.W.; Scott, R.W.J. Stable and Recyclable Au 25 Clusters for the Reduction of 4-Nitrophenol. Chem. Commun. 2013, 49, 276-278. [CrossRef] [PubMed]

37. Tan, Y.; Liu, X.Y.; Zhang, L.; Wang, A.; Li, L.; Pan, X.; Miao, S.; Haruta, M.; Wei, H.; Wang, H.; et al. $\mathrm{ZnAl}-\mathrm{Hydrotalcite-Supported} \mathrm{Au}_{25}$ Nanoclusters as Precatalysts for Chemoselective Hydrogenation of 3-Nitrostyrene. Angew. Chem. Int. Ed. 2017, 56, 2709-2713. [CrossRef] 
38. Tan, Y.; Liu, X.Y.; Li, L.; Kang, L.; Wang, A.; Zhang, T. Effects of Divalent Metal Ions of Hydrotalcites on Catalytic Behavior of Supported Gold Nanocatalysts for Chemoselective Hydrogenation of 3-Nitrostyrene. J. Catal. 2018, 364, 174-182. [CrossRef]

39. Zhu, Y.; Qian, H.; Drake, B.A.; Jin, R. Atomically Precise $\mathrm{Au}_{25}(\mathrm{SR})_{18}$ Nanoparticles as Catalysts for the Selective Hydrogenation of $\alpha, \beta$-Unsaturated Ketones and Aldehydes. Angew. Chem. Int. Ed. 2010, 122, 1317-1320. [CrossRef]

40. Kannan, S. Influence of Synthesis Methodology and Post Treatments on Structural and Textural Variations in $\mathrm{MgAlCO}_{3}$ Hydrotalcite. J. Mater. Sci. 2004, 39, 6591-6596. [CrossRef]

41. Sing, K.S.W.; Williams, R.T. Physisorption Hysteresis Loops and the Characterization of Nanoporous Materials. Adsorpt. Sci. Technol. 2004, 22, 773-784. [CrossRef]

42. Stasiak-Włodarczyk, M.; Jamroz, J. Specific Surface Area and Porosity of Starch Extrudates Determined from Nitrogen Adsorption Data. J. Food Eng. 2009, 93, 379-385. [CrossRef]

43. Gao, J.; Fan, G.; Yang, L.; Cao, X.; Zhang, P.; Li, F. Oxidative Esterification of Methacrolein to Methyl Methacrylate over Gold Nanoparticles on Hydroxyapatite. ChemCatChem 2017, 9, 1230-1241. [CrossRef]

44. Kepinski, L. Thermal Stability of $\mathrm{Ce}_{0.5} \mathrm{Gd}_{0.5} \mathrm{O}_{1.75}$ Nanoparticles in Contact with an Amorphous $\mathrm{SiO}_{2}$. J. Non-Cryst. Solids 2015, 409, 170-177. [CrossRef]

45. Feng, J.; Ma, C.; Miedziak, P.J.; Edwards, J.K.; Brett, G.L.; Li, D.; Du, Y.; Morgan, D.J.; Hutchings, G.J. Au-Pd Nanoalloys Supported on Mg-Al Mixed Metal Oxides as a Multifunctional Catalyst for Solvent-free Oxidation of Benzyl Alcohol. Dalton. Dalton Trans. 2013, 42, 14498-14508. [CrossRef]

46. Caux, M.; Menard, H.; AlSalik, Y.M.; Irvine, J.T.S.; Idriss, H. Photo-Catalytic Hydrogen Production over $\mathrm{Au} / \mathrm{g}-\mathrm{C}_{3} \mathrm{~N}_{4}$ : Effect of Gold Particle Dispersion and Morphology. Phys. Chem. Chem. Phys. 2019, 21, 15974-15987. [CrossRef]

47. Tang, H.; Liu, F.; Wei, J.; Qiao, B.; Zhao, K.; Su, Y.; Jin, C.; Li, L.; Liu, J.; Wang, J.; et al. Ultrastable Hydroxyapatite/Titanium-Dioxide-Supported Gold Nanocatalyst with Strong Metal-Support Interaction for Carbon Monoxide Oxidation. Angew. Chem. Int. Ed. 2016, 55, 10606-10611. [CrossRef]

48. Hsieh, P.T.; Chen, Y.C.; Kao, K.S.; Wang, C.M. Luminescence Mechanism of ZnO Thin Film Investigated by XPS Measurement. Appl. Phys. A 2007, 90, 317-321. [CrossRef]

49. Chen, Z.; Zhan, G.; Lu, Z. Solvothermal Synthesis and Conductive Properties of Nanorod-constructed Al-Doped ZnO Microflowers. J. Mater. Sci. Mater. 2014, 25, 1724-1730. [CrossRef]

50. Chen, J.L.; Dong, X.Y.M.; Shi, C.L.; Li, S.H.; Wang, Y.; Zhu, J.H. Fabrication of strong solid base FeO-MgO for warm $\mathrm{CO}_{2}$ capture. Clean 2019, 47, 1800447.

51. Umchoo, W.; Sriakkarin, C.; Donphai, W.; Warakulwit, C.; Poo-arporn, Y.; Jantaratana, P.; Witoon, T.; Chareonpanich, M. Green and sustainable methanol production from $\mathrm{CO}_{2}$ over magnetized $\mathrm{FeCu} / \mathrm{core}$-shell and infiltrate mesoporous silica-aluminosilicates. Energy Convers. Manag. 2018, 159, 342-352. [CrossRef]

52. Campelo, J.M.; Climent, M.S.; Marinas, J.M. Michael addition of nitromethane to 3-buten-2-one catalyzed by potassium fluoride supported on $\mathrm{Al}_{2} \mathrm{O}_{3}, \mathrm{ZnO}, \mathrm{SnO}_{2}$, sepiolite, $\mathrm{AlPO}_{4}, \mathrm{AlPO}_{4}-\mathrm{Al}_{2} \mathrm{O}_{3}$ and $\mathrm{AlPO}_{4}-\mathrm{ZnO}$. React. Kinet. Catal. Lett. 1992, 47,7-11. [CrossRef]

53. Antunes, W.M.; de Oliveira Veloso, C.; Henriques, C.A. Transesterification of soybean oil with methanol catalyzed by basic solids. Catal. Today 2008, 133, 548-554. [CrossRef]

54. Tanabe, K.; Yamaguchi, T. Basicity and acidity of solid surfaces. J. Res. Inst. Catal. 1964, 11, 179-184.

55. Bancquart, S.; Vanhove, C.; Pouilloux, Y.; Barrault, J. Glycerol transesterification with methyl stearate over solid basic catalysts: I. Relationship between activity and basicity. Appl. Catal. A 2001, 218, 1-11. [CrossRef]

56. Drouilly, C.; Krafft, J.M.; Averseng, F.; Lauron-Pernota, H.; Bazer-Bachi, D.; Chizallet, C.; Lecocq, V.; Costentin, G. Role of oxygen vacancies in the basicity of $\mathrm{ZnO}$ : From the model methylbutynol conversion to the ethanol transformation application. Appl. Catal. A 2013, 453, 121-129. [CrossRef]

57. Dimitratos, N.; Lopez-Sanchez, J.A.; Morgan, D.; Carley, A.; Prati, L.; Hutchings, G.J. Solvent free Liquid Phase Oxidation of Benzyl Alcohol Using Au Supported Catalysts Prepared Using a Sol Immobilization Technique. Catal. Today 2007, 122, 317-324. [CrossRef]

58. Wang, H.; Gu, X.K.; Zheng, X.; Pan, H.; Zhu, J.; Chen, S.; Cao, L.; Li, W.X.; Lu, J. Disentangling the Size-Dependent Geometric and Electronic Effects of Palladium Nanocatalysts Beyond Selectivity. Sci. Adv. 2019, 5, 6413-6421. [CrossRef] 
59. Skupien, E.; Berger, R.; Santos, V.P.; Gascon, J.; Makkee, M.; Kreutzer, M.T.; Kooyman, P.J.; Moulijn, J.A.; Kapteijn, F. Inhibition of a Gold-Based Catalyst in Benzyl Alcohol Oxidation: Understanding and Remediation. Catalyst 2014, 4, 89-115. [CrossRef]

60. Thompson, D.T. Catalysis by Gold. Catal. Rev.-Sci. Eng. 1999, 41, 319-388.

61. Suchomel, P.; Kvitek, L.; Prucek, R.; Panacek, A.; Halder, A.; Vajda, S.; Zboril, R. Simple Size-Controlled Synthesis of Au Nanoparticles and their Size-Dependent Catalytic Activity. Sci. Rep. 2018, 8, 4589-4599. [CrossRef]

62. Qiao, B.; Liang, J.X.; Wang, A.; Xu, C.Q.; Li, J.; Zhang, T.; Liu, J. Ultrastable single-atom gold catalysts with strong covalent metal-support interaction (CMSI). Nano Res. 2015, 8, 2913-2924. [CrossRef]

C 2020 by the authors. Licensee MDPI, Basel, Switzerland. This article is an open access article distributed under the terms and conditions of the Creative Commons Attribution (CC BY) license (http://creativecommons.org/licenses/by/4.0/). 